\title{
Novel targeted therapies of T cell lymphomas
}

\author{
Katarzyna Iżykowska, Karolina Rassek, Dorota Korsak and Grzegorz K. Przybylski (D)
}

\begin{abstract}
T cell lymphomas (TCL) comprise a heterogeneous group of non-Hodgkin lymphomas (NHL) that often present at an advanced stage at the time of diagnosis and that most commonly have an aggressive clinical course. Treatment in the front-line setting is most often cyclophosphamide, doxorubicin, vincristine, and prednisone (CHOP) or CHOP-like regimens, which are effective in B cell lymphomas, but in TCL are associated with a high failure rate and frequent relapses. Furthermore, in contrast to $\mathrm{B}$ cell $\mathrm{NHL}$, in which substantial clinical progress has been made with the introduction of monoclonal antibodies, no comparable advances have been seen in TCL. To change this situation and improve the prognosis in $\mathrm{TCL}$, new gene-targeted therapies must be developed. This is now possible due to enormous progress that has been made in the last years in the understanding of the biology and molecular pathogenesis of TCL, which enables the implementation of the research findings in clinical practice. In this review, we present new therapies and current clinical and preclinical trials on targeted treatments for TCL using histone deacetylase inhibitors (HDACi), antibodies, chimeric antigen receptor T cells (CARTs), phosphatidylinositol 3-kinase inhibitors (PI3Ki), anaplastic lymphoma kinase inhibitors (ALKi), and antibiotics, used alone or in combinations. The recent clinical success of ALKi and conjugated anti-CD30 antibody (brentuximab-vedotin) suggests that novel therapies for TCL can significantly improve outcomes when properly targeted.
\end{abstract}

Keywords: TCL, PTCL, SPTCL, Targeted therapy, HDACi, Antibodies, CART, Alki, PI3Ki

\section{Background}

$\mathrm{T}$ cell lymphomas (TCL) are a very heterogeneous group of lymphoid malignancies derived from mature $\mathrm{T}$ cells differing by localization, pathological features, and clinical presentation. TCL represent approximately $12 \%$ of all non-Hodgkin lymphomas (NHLs) and are divided into cutaneous TCL (CTCL) and peripheral TCL (PTCL), which themselves are subdivided into nodal or extranodal (systemic) types. CTCL derive from skin-homing $\mathrm{T}$ cells and consist of mycosis fungoides (MF), Sézary syndrome (SS), primary cutaneous CD30-positive $\mathrm{T}$ cell lymphoproliferative disorders: lymphomatoid papulosis (LP) and

*Correspondence: grzegorz.przybylski@igcz.poznan.pl Institute of Human Genetics, Polish Academy of Sciences, Strzeszyńska 32, 60-479 Poznań, Poland anaplastic large cell lymphoma (ALCL), cutaneous $\gamma \delta$ TCL (CGD-TCL), cutaneous CD8-positive aggressive epidermotropic cytotoxic TCL (CD8 + AECTCL), and cutaneous CD4-positive small/medium TCL (CSMTCL). Nodal PTCL consist of peripheral TCL not otherwise specified (PTCL-NOS), angioimmunoblastic TCL (AITK), and anaplastic large cell lymphoma (ALCL): ALK positive and ALK negative. Extranodal PTCL consist of extranodal NK/T cell lymphoma nasal type (ENKTL), enteropathy-associated TCL (EATCL), hepatosplenic TCL (HSTCL), and subcutaneous panniculitis-like TCL (SPTCL) [1]. The common features of TCL are aggressive course and poor response to therapy with the exception of ALK + ALCL. Despite the enormous progress that has been made in the twenty-first century in the treatment of hematological malignancies in the majority of TCL cases, the original author(s) and the source, provide a link to the Creative Commons licence, and indicate if changes were made. The images or other third party material in this article are included in the article's Creative Commons licence, unless indicated otherwise in a credit line to the material. If material is not included in the article's Creative Commons licence and your intended use is not permitted by statutory regulation or exceeds the permitted use, you will need to obtain permission directly from the copyright holder. To view a copy of this licence, visit http://creativecommons.org/licenses/by/4.0/. The Creative Commons Public Domain Dedication waiver (http://creativeco mmons.org/publicdomain/zero/1.0/) applies to the data made available in this article, unless otherwise stated in a credit line to the data. 
outcome is still unsatisfactory, and the disease remains incurable. Therefore, new targeted treatment modalities for TCL patients are currently being extensively explored. Those emerging treatments are based on histone deacetylase inhibitors (HDACi), antibodies (Ab), chimeric antigen receptor T cells (CARTs), phosphatidylinositol 3-kinase inhibitors (PI3Ki), anaplastic lymphoma kinase inhibitors (ALKi) and antibiotics, used alone, in combinations with each other, or in combination with classical chemotherapy (Figs. 1 and 2).

\section{Histone deacetylase inhibitors (HDACi)}

Histone deacetylases (HDACs) are a group of enzymes involved in the epigenetic regulation of gene expression. They remove the acetyl group from histones and, as a result, modulate the chromatin structure and change the accessibility of transcription factors to their target DNA sequence [2]. There are four classes of HDAC: class I HDACs (HDAC1, 2, 3, 8) are ubiquitously expressed in all cell types and are localized in the nucleus, class II HDACs (HDAC 4, 5, 6, 7, 9, 10) are more tissue specific and can be localized in the nucleus and cytoplasm, class III (called sirtuins; SIRT1-7) and class IV (HDAC11). The balance between the histone acetylation by histone acetylases (HAT enzymes) and deacetylation by HDACs is often disturbed in cancer leading to altered gene expression and malignant transformation. Compounds that block HDAC, HDAC inhibitors (HDACi), were introduced to the treatment of several types of cancer, mainly in $\mathrm{T}$ cell lymphomas. HDACi have the

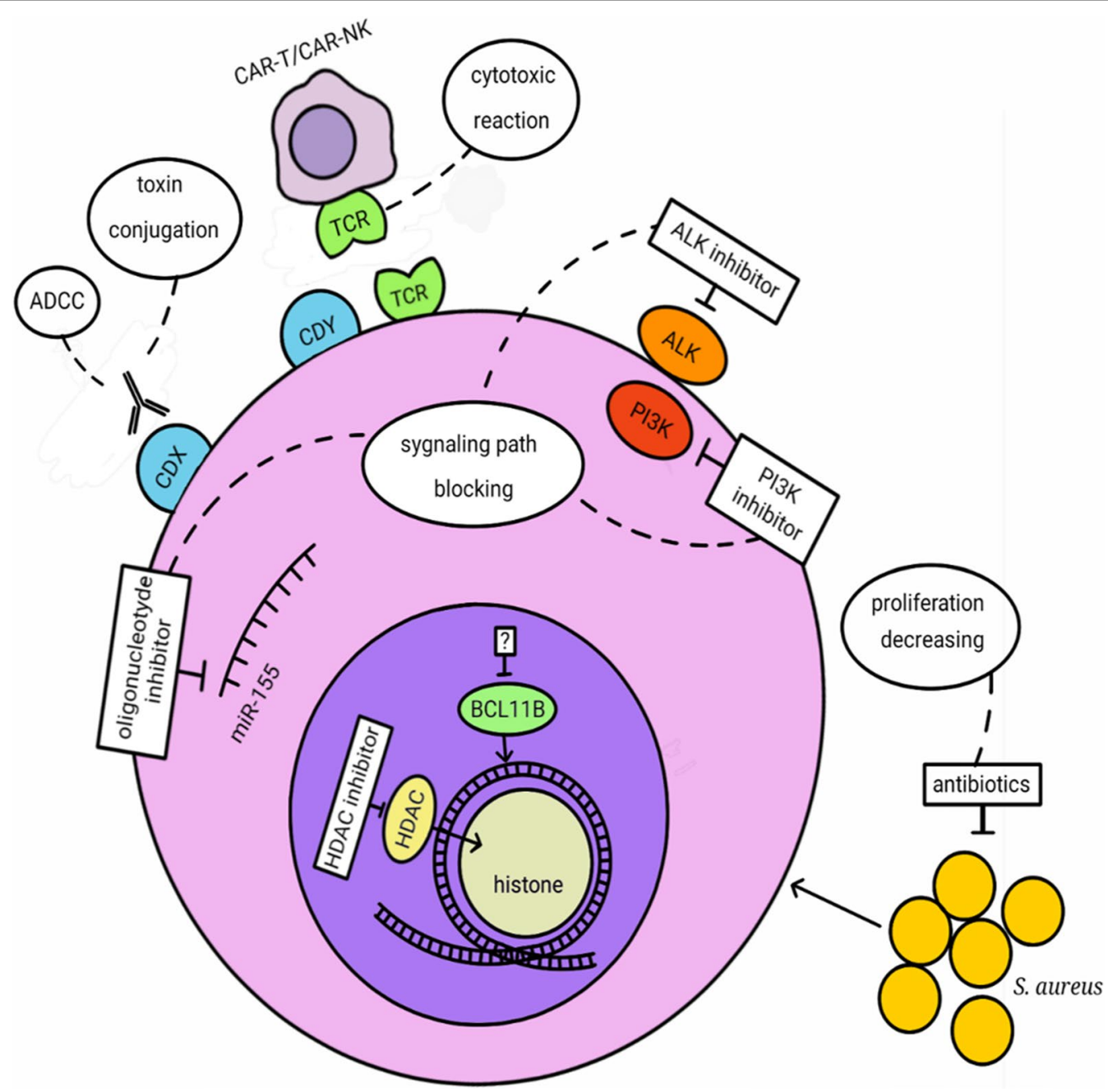

Fig. 1 Targeted T cell lymphoma therapies mode of action. ADCC: Antibody-dependent cellular cytotoxicity, CD: cluster of differentiation antigens CDX: CD16, CD25, CD30, CD38, CD47, CD52, KIR3DL2 (CD158k), CCR4 (CD194), ICOS (CD278), CAMD1; CDY: CD4, CD5, CD7, CD30, HDAC: histone deacetylase, ALK: anaplastic lymphoma kinase, PI3K: phosphoinositide 3-kinases, BCL11B: B cell lymphoma/leukemia 11B 


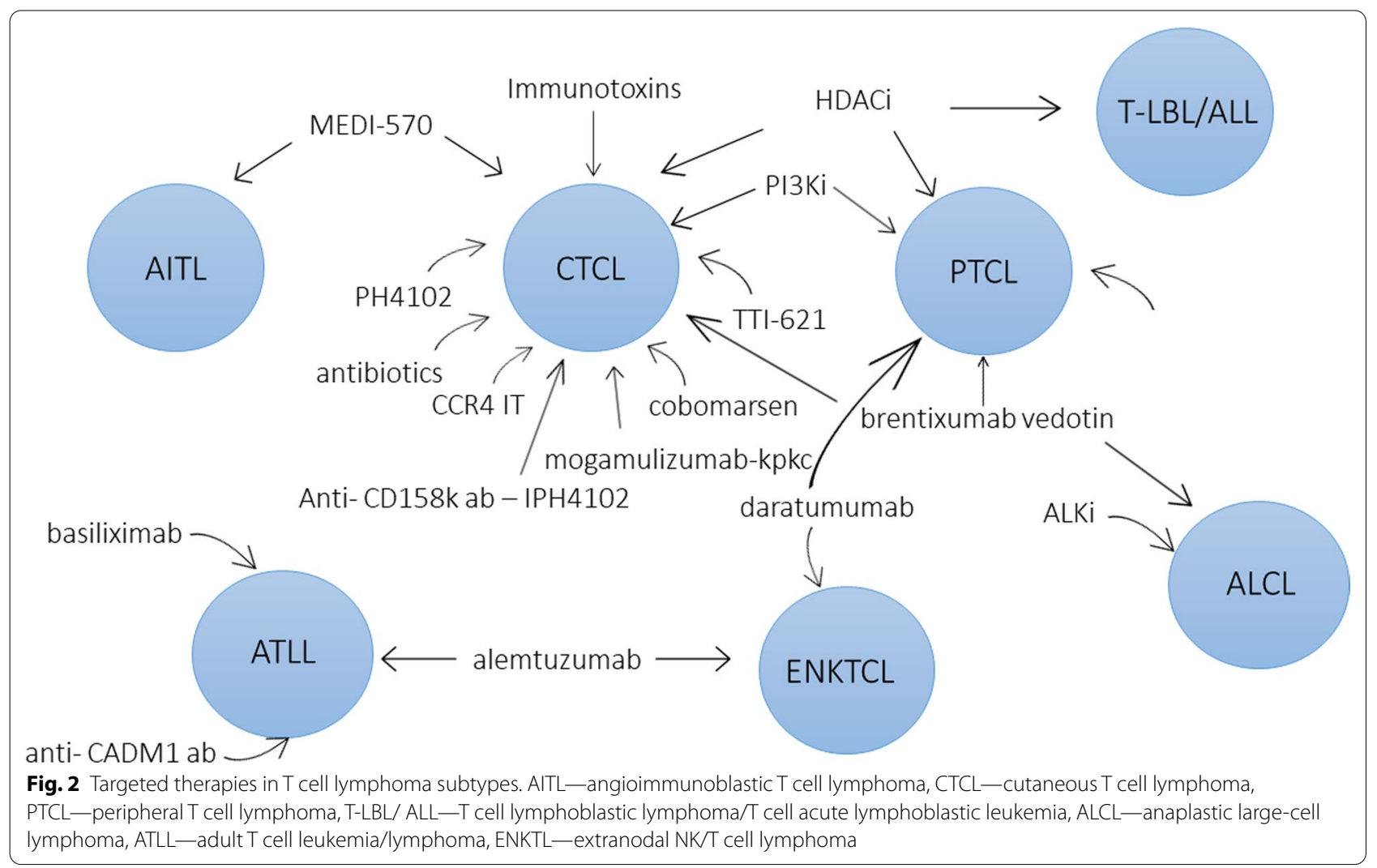

capacity to increase acetylation of histones and other proteins, inducing changes in chromatin structures and the promotion of expression of tumor-suppressor genes, apoptosis, and, as a result antitumor activity [3]. HDAC inhibitors may act against all types of HDACs (pan-inhibitors) or, specifically, against some of the HDAC isoforms (HDAC isoform-selective inhibitors).

The mechanism of action of HDACi can be different; it depends on the type of cancer, the type of HDACi used, and its dose. Multiple cellular processes are activated upon HDACi treatment [2,4]. Cell cycle arrest is induced by increased expression of genes like p21, p53, and RUNX3. Both intrinsic and extrinsic apoptotic pathways are activated, through either death receptors (TRAIL, DR5, Fas, TNF) or the activation of proapoptotic genes like Bid, Bad, and Bim. Autophagy is the mechanism of the anti-cancer effect of HDACi through acetylation of autophagy-related proteins, overexpression of autophagy-related genes, and also as a result of ROS production. HDACi also alters the expression of noncoding RNAs, genes involved in cell growth and differentiation (including protein kinases), major histocompatibility complex (MHC) and costimulatory molecules, and genes involved in angiogenesis and the metastatic process $[2,5]$. In 2017, ATACseq analysis showed that clinical response to HDACi is strongly associated with a gain in chromatin accessibility [6]. HDACi caused distinct chromatin responses in malignant and normal CD4 $+\mathrm{T}$ cells, reprogramming the first ones toward normalcy. The pattern of accessible chromatin could be used to predict clinical response to HDACi [6].

\section{FDA-approved HDACi}

Suberoylanilide hydroxamic acid (SAHA, Vorinostat)

Vorinostat was the first drug to be approved by the FDA, since 2006, for CTCL patients with progressive, persistent, and recurrent disease on or following two systemic therapies (FDA). Vorinostat is an oral competitive inhibitor of class I/II HDAC enzymes [3]. In two phase-II trials, vorinostat $400 \mathrm{mg} /$ day was safe and effective, with an overall response rate (ORR) of $24-30 \%$ in refractory advanced patients with CTCL including SS [7-9]. However, in the phase-III MAVORIC trial, vorinostat was compared with mogamulizumab in MF/SS patients and an ORR was only $5 \%$, which was significantly lower than that of mogamulizumab (28\%) [10]. The most common and serious toxicity side effects were thrombocytopenia, anemia, dehydration, nausea/vomiting, hypotension, infection, sepsis, pulmonary embolism, and deep venous thrombosis, but they were reversible upon discontinuation of the drug [11]. 


\section{Belinostat (PXD-101)}

The FDA approved Belinostat in 2014 for the treatment of patients with relapsed or refractory PTCL. In a phaseII clinical trial, 24 PTCL patients and 29 CTCL patients (17MF/7SS) were administrated $1,000 \mathrm{mg} / \mathrm{m}^{2}$ intravenously on days $1-5$ every 3 weeks. The ORRs were $25 \%$ for PTCL and $14 \%$ for CTCL. In total, $77 \%$ of patients experienced the following side effects: nausea, vomiting, infusion site pain, and dizziness [12]. In the pivotal phase-II BELIEF (CLN-19) study with patients with relapsed or refractory PTCL, ORR was similar: $25.8 \%$ (31 of 120), including 13 complete responses (CR) (10.8\%) and 18 partial responses (PR) (15\%) [13]. The most common grade $3 / 4$ adverse events were anemia, thrombocytopenia, dyspnea, and neutropenia. In 2018, Allen and Lechowicz conducted a systemic review to assess the safety and efficacy of belinostat [14]. A safety analysis was performed on 512 patients with different relapsed malignancies from 16 different studies, and an efficacy analysis was focused on patients with relapsed PTCL (144 patients). The safety analysis showed that among all adverse events, the most common were fatigue, nausea, and vomiting, while overall grade $3 / 4$ hematologic toxicity was low (6.4\%). The efficacy analysis confirmed the ORR to be $25.7 \%$, with $10.4 \%$ complete remissions and $15.3 \%$ partial responses.

\section{Romidepsin}

Romidepsin was FDA-approved in 2009 for CTCL patients who have received at least one prior systemic therapy. It is administered intravenously and inhibits class I HDAC selectively. Seventy-one CTCL patients were included in a phase-II study conducted by Piekarz et al. in 2009 [15]. The overall response rate was 34\%; four patients experienced complete responses, while partial responses were observed in 20 patients. Overall, romidepsin was well tolerated, with the main toxicities observed being fatigue, nausea, and vomiting. Another multicenter, international, pivotal study of romidepsin in refractory CTCL was conducted in 2010 [16]. Ninety-six patients were enrolled, most of whom had advanced-stage disease. The ORR was $34 \%$, and six patients reached a complete response (CR). A clinically meaningful improvement in pruritus was observed in $43 \%$ of patients, lasting for a 6 -month period. The third study, in 2011 [17], enrolled patients with CTCL and PTCL. CR was observed in 8 and PE in 9 of 45 patients, while the ORR was $38 \%$. In both studies, drug-related adverse events were as previously described, mainly involving gastrointestinal disturbances. Romidepsin was also proven to have a good response in patients with relapsed or refractory CTCL with cutaneous tumors and/ or folliculotropic disease involvement with less favorable outcomes. The ORR was $45 \%$ and $60 \%$, respectively, and there was a significant reduction in pruritis [18]. Pruritis reduction upon romidepsin treatment was confirmed even in patients without any objective clinical response [19]. The most recent multicenter retrospective study of 53 patients with relapsed or refractory PTCL and CTCL treated with romidepsin [20] showed that the ORR and the CR rates for PTCL were $33 \%$ and $12.5 \%$, respectively, and for CTCL, $25 \%$ and $0 \%$, respectively. The most common grade $3 / 4$ adverse events included hematological toxicity and infections.

\section{Panobinostat}

The FDA approved panobinostat for the treatment of multiple myeloma (MM) in 2015. It is a pan HDACi that is orally bioavailable. To check the efficacy of this HDACi in CTCL, a phase-II study was conducted in 2012 [21]. Oral panobinostat demonstrated clinical activity in MF or SS patients regardless of prior bexarotene treatment. An ORR of $17.3 \%$ for all patients was detected, while $74 \%$ showed an improvement in the severity of their skin disease. Panobinostat was generally well tolerated, with thrombocytopenia, diarrhea, fatigue, and nausea being the most common adverse events. In 2013, another study was conducted to verify the safety, pharmacokinetics (PK), and preliminary activity of panobinostat in different hematologic malignancies, and promising single-agent activity was noted in patients with MF [22].

\section{HDACi in clinical trials \\ Chidamide}

Chidamide was approved in December 2014 by the China Food and Drug Administration (CFDA) for the treatment of relapsed or refractory PTCL. It is a selective inhibitor of HDAC1, 2, 3, and 10 and is administrated orally [23]. Seventy-nine patients with PTCL were enrolled in a first phase-II study conducted in 2015 . The ORR was $28 \%$ (22 of 79 ) including $14 \%$ (11 of 79) with complete response/ unconfirmed complete response. Most adverse events were grade 1 or 2 ; grade 3 and 4 , which occurred in $\geq 10 \%$ of patients, were thrombocytopenia, leucopenia, and neutropenia $[24,25]$.

\section{Resminostat}

Resminostat is an orally bioavailable pan-HDAC inhibitor specifically targeting class I HDACs. It was tested in clinical trials for hepatocellular carcinoma patients [26]. Now there are plans to test it in patients with advancedstage (Stage IIB-IVB) MF or SS who have achieved disease control with systemic therapy-the RESMAIN Study (NCT02953301). 


\section{Quisinostat}

Quisinostat is a potent "second-generation" class I HDAC inhibitor with prolonged pharmacodynamic response in vivo [27]. It was shown to have the potential to inhibit cancer cell self-renewal [28]. A clinical study on Quisinostat in patients with previously treated stage Ib-IVa CTCL (NCT01486277) was conducted, though with no results available so far.

\section{AR-42}

AR-42 (Arno Therapeutics) is an orally bioavailable, hydroxamate-tethered phenylbutyrate-derived small molecule that targets and inhibits class I and IIB HDACs. An antitumor activity of this compound in solid tumors and hematological malignancies was detected in vitro, and in 2017 the results of the phase I clinical trials were published [29]. The safety of this dug was confirmed, and the maximum tolerated dose (MTD) was established: $40 \mathrm{mg}$ administered orally three times weekly, for three weeks of a 28-day cycle.

\section{HDACi combined with other therapies}

The response to treatment with HDACi is $30 \%$, which is still not satisfactory. Many studies have been conducted to verify the combination of HDACi with other drugs and protocols in order to achieve higher response, especially in advanced-stage patients.

Romidepsin has been tested together with both radiotherapy and chemotherapy in patients with TCL. It was shown that in advanced MF patients, localized electron beam radiation with romidepsin therapy produced a fast and durable response and that significantly lower doses of electron beam radiation effectively treated symptomatic lesions in studied patients [30]. Also, a total skin electron beam therapy (TSEBT) with romidepsin in advanced SS/MF patients was shown to be a safe option with no additional adverse events [31]. The safety and efficacy of romidepsin and other anti-cancer drugs have been investigated. Seven PTCL patients were enrolled to study the romidepsin-bendamustine combination, and among them, two achieved complete remission [32]. Eighteen patients were enrolled in a phase-I study of romidepsin and ifosfamide, carboplatin, and etoposide for the treatment of patients with relapsed or refractory PTCL [33]. The outcomes were promising. The ORR was 93\%: 12 (80\%) patients achieved CR and 2 patients achieved (13\%) partial remission (PR); one (7\%) patient achieved stable disease (SD). For the combination of romidepsin and pralatrexate, the ORR was $57 \%(13 / 23)$ across patients with different types of relapsed/refractory lymphomas, and $71 \%(10 / 14)$ in PTCL, while each drug separately usually gives an ORR of $25 \%$ and $29 \%$, respectively [34]. The study suggested that such an approach could be an effective and safe platform for patients with PTCL; therefore, the phase-II clinical trial is now being conducted (NCT01947140).

Moreover, romidepsin could be used together with other epigenetic drugs like 5-azacytidine (AZA). Thirtyone patients with lymphoid malignancies were enrolled in a phase-I study to assess the synergistic effect between oral AZA, a hypomethylating agent, and romidepsin [35]. The overall response rates in all, non- $\mathrm{T}$ cell and $\mathrm{T}$ cell lymphoma patients were $32 \%, 10 \%$, and $73 \%$, respectively, and the complete response rates were $23 \%, 5 \%$, and $55 \%$, respectively. The combination of two drugs was more active in patients with PTCL. Among adverse effects, thrombocytopenia, neutropenia, and pleural effusion were the most severe. The clinical trial is ongoing (Phase I/IIa Study of the Oral 5-Azacitidine in Combination With the Histone Deacetylase Inhibitor Romidepsin for the Treatment of Patients With Relapsed and Refractory Lymphoid Malignancies NCT01998035). AZA was also tested with vorinostat and the combination of gemcitabine/busulfan/melphalan in patients with different types of lymphoma, including $\mathrm{T}$ cell types [36]. The previous observation showed that treatment with vorinostat/Gem/ $\mathrm{Bu} / \mathrm{Mel}$ increased the activity of methyltransferases and that further inhibition of DNA methyltransferases could enhance the cytotoxicity of this combination of drugs. The study showed higher CR rates upon azacitidine treatment combined with vorinostat/Gem/Bu/Mel especially in patients with refractory or poor prognosis relapsed HL and $\mathrm{NH}$.

A phase-I clinical trial combining romidepsin and alisertib has been conducted in patients with relapsed/ refractory aggressive $B$ cell and $T$ cell lymphoma [37]. Alisertib is a drug that inhibits aurora A kinase (AAK), a serine/threonine kinase required for cell division. The ORR for this drug alone is $27 \%$ in patients with relapsed refractory aggressive B cell and T cell NHL and even higher in patients with PTCL, between 33 and 50\% [37]. However, the majority of responses are partial and shortlasting. It was shown that AAK inhibitors and HDACi have synergistic activity; HDACi create a pro-apoptotic environment and sensitize cells to AAK inhibitors. However, in a study in which romidepsin and alisertib were used together in patients with relapsed/refractory aggressive B cell and T cell lymphoma, the ORR was only $28 \%$.

In a phase-I study, duvelisib in combination with romidepsin or bortezomib was used to determine the maximum tolerated dose in relapsed/refractory TCL patients (NCT02783625) [38]. Duvelisib (IPI-145) is an oral inhibitor of PI3K- $\delta$ and PI3K- $\gamma$. Phosphoinositide3-kinases (PI3K) are involved in cell signaling and regulate multiple cellular functions, while PI3K- $\delta$ and PI3K- $\gamma$ isoforms are crucial for $\mathrm{T}$ cell functioning. Inhibition 
of PI3K is a therapeutic strategy for PTCL and CTCL. The ORR response of duvelisib is $47 \%$ in PTCL patients, while in combination with romidepsin it was only slightly higher (50\%), but well tolerated. Patients with CTCL and PTCL were also enrolled in a clinical trial to assess the combination of romidepsin with lenalidomide. Lenalidomide is an immunomodulatory agent that has antiproliferative and antineoplastic activity in malignant cells [38]. The ORR in PCTL patients treated with lenalidomide was $22-26 \%$, while when romidepsin was used, the ORR was $50 \%$ [39]. A phase-II study in untreated PTCL with lenalidomide and romidepsin is ongoing (NCT02232516). Carfilzomib, a proteasome inhibitor used in combination with the previous two, did not increase the ORR in PCTL patients.

Multiple HDACi are also being incorporated into hematopoietic cell transplantation (HCT) approaches, in both the frontline and maintenance settings in patients with PTCLs [40]. In a recent phase-II multicenter trial, the efficacy of romidepsin was evaluated as a maintenance therapy after auto-HCT for patients with PTCL. Two patient cohorts were included: patients transplanted in CR1/PR1 $(n=25)$ and patients transplanted in CR2/ PR2 or later $(n=7)$ [41]. In the first group, the estimated 2 -year progression-free survival (PFS) was 49\%; among this group angioimmunoblastic T cell lymphoma (AITL) patients were highly represented, with a 2-year PFS of $44 \%$. In the second group, estimated 2-year PFS was $47 \%$. However, PFS improvement with romidepsin maintenance was considered to be not significant, as PFS after AHCT itself is $36-45 \%$.

The synergistic interaction between romidepsin and liposomal doxorubicin (LD) in both CTCL cell lines and primary CTCL cells was detected, and it was confirmed in the phase-I study in relapsed/refractory CTCL and PTCL [42]. This combination provided an ORR of $70 \%$ in MF and SS patients, which is a significant improvement, and only $27 \%$ in PTCL patients.

Chidamide is now being extensively tested in a preclinical and in clinical trials in combination with other drugs. Studies showed that chidamide treatment with low-dose doxorubicin exhibited a synergism effect on cell growth and apoptosis in two PTCL cell lines [43]. In a clinical trial in which chidamide and chemotherapy were used in patients with refractory or relapsed $\mathrm{T}$ cell acute lymphoblastic lymphoma/leukemia (T-LBL/ALL), the sensitivity of T-LBL/ALL cell to chemotherapy drugs was improved and the complete response and ORR increased [44]. A large, multicenter study was performed in China on chidamide in relapsed or refractory peripheral $\mathrm{T}$ cell lymphoma. In total, 383 patients were enrolled; ORR for chidamide used as a monotherapy was $39 \%$, while when chidamide was used with chemotherapy, the ORR was $51 \%$ [24].

\section{$\mathrm{HDACi}$-future perspective}

Treatment with HDACi is promising, yet there are still several challenges. One of them is the improvement of drug delivery. The efficient oral delivery of hydrophobic molecules to target tissues is limited [45]. HDACi like vorinostat have poor solubility and permeability and, as a result, have low bioavailability. A recent study by Meka et al. (2018) [45] investigated the effect of the encapsulation of vorinostat within functionalized mesoporous silica nanoparticles (MSNs) on its solubility, permeability, and anti-cancer activity. All parameters were enhanced 2.6-fold and fourfold, respectively, and increased HDAC inhibition, apoptosis induction and altered gene expression in cancer cell lines were observed. To improve the selectivity of Vorinostat to cancer cells, Bhadat et al. (2018) generated a novel SAHA prodrug (SAHA-OBP) that is activated in the presence of hydrogen peroxide, a reactive oxygen species (ROS) known to be overexpressed in cancer cells [46]. The analysis showed that the SAHA-OBP prodrug is activated inside cancer cells due to the high intracellular ROS levels. The reaction between SAHA-OBP and $\mathrm{H}_{2} \mathrm{O}_{2}$ produces active SAHA, which leads to the inactivation of cytosolic HDAC6, the hyperacetylation of tubulin, and, in the end, apoptosis. In another study, a synthesized SAHA-based prodrug polymer was designed, denoted as POEG-b-PSAHA. These amphiphilic polymers were shown to self-assemble into prodrug micelles and serve as nanocarriers for doxorubicin delivery [47] and increased cytotoxicity of those drugs toward tumor cells.

Another huge challenge is the resistance of cancer cells to HDACi. The mechanisms behind that resistance are still poorly known. Recently, Andrews et al. [48] showed differences in the acetylation levels of gene regulatory elements between HDACi-sensitive and HDACi-resistant CTCL patients. These changes were linked to the different expression of genes involved in the cell cycle, apoptosis, cytokine/chemokine signaling, and cell adhesion/migration pathways. In HDACi-resistant samples, increased acetylation was particularly significant near potential MF/SS oncogenes CCR6, CXCR4, and LAIR2 [48]. The last one was suggested to be used as an HDACiresistant marker. What's interesting, single-cell analysis showed that it is possible to distinguish subpopulations of SS cells that are resistant to HDACi treatment and lead to a relapse of the disease [49]. This knowledge could be useful in planning the treatment based on multiple agents targeting different populations of malignant cells. The search for more effective treatments is ongoing. Recently, bromodomain and extra-terminal motif inhibitors (BETi) 
are being tested in the therapy of CTCL $[50,51]$. BET proteins are other epigenetic modulators, so-called readers, and BET inhibitors prevent interaction between BET proteins and acetylated histones and transcription factors. The preclinical findings on CTCL cell lines showed that epigenetic modulation with a combination of BETi and HDACi could be a beneficial therapy for CTCL. Those two drugs were shown to promote cell apoptosis and inhibit cell proliferation. Another drug that could be used in combination with HDACi is a $\mathrm{BCl} 2$ inhibitor, Venetoclax [52]. A subset of CTCL patients showed high sensitivity to Venetoclax; also, a synergistic effect was observed when venetoclax was combined with romidepsin and vorinostat. A synergistic effect in the induction of SS tumor cells was also detected between Vorinostat and the anticancer antibiotic Mithramycin (Plicamycin, MTR, marketed as Mithracin $\left.{ }^{\circledR}\right)$, a direct inhibitor of the binding of Sp1 family factors to GC-rich promoters [53].

\section{Antibody-based therapies}

Antibody-based therapies became one of the most important areas of treatment strategies for TCL. An unquestionable advantage of using monoclonal antibodies $(\mathrm{mAb})$ compared to other strategies is their high specificity and, therefore, limited adverse effects. To date, two FDA and EMA mAb-based medicines are approved for TCL treatment; however, a number of antibody-based drugs are undergoing clinical trials, with strategies focusing on $\mathrm{mAb}$ not only alone but also in combination with other drugs in order to increase clinical efficacy.

\section{FDA-approved antibody-based drugs}

\section{Brentuximab vedotin-anti-CD30 antibody-drug} conjugate

CD30 (tumor necrosis factor receptor superfamily, member 8; TNFRSF8) is a transmembrane protein belonging to the tumor necrosis factor receptor (TNFR) superfamily. CD30 normal expression is restricted to a small subpopulation of activated $\mathrm{B}, \mathrm{T}$, and natural killer (NK) cells; however, it can be induced by a viral infection. Indeed, CD30 expression was reported on lymphocytes infected by such viruses as human immunodeficiency virus (HIV), human T-lymphotropic virus-1 (HTLV-1), or EpsteinBarr virus (EBV). The exact function of CD30 in human physiology has not yet been discovered; however, it was shown that depending on the context and target cells, CD30 expression may either suppress replication and lead to apoptosis or promote cell proliferation and survival [54]. In addition, CD30 can regulate peripheral T-lymphocyte immune responses by controlling $\mathrm{T}$ cell survival and downregulating cytolytic capacity as well as controlling T-helper 1 and 2 (Th1 and Th2) responses in autoimmune and inflammatory conditions by interaction with its ligand (CD30L) [55-57]. CD30 was also reported to stimulate $\mathrm{T}$ cells to produce such cytokines as IL-2, TNF, and IFN- $\gamma$ [58]. CD30 expression is present on the tumor cells of most classical Hodgkin lymphomas as well as anaplastic large cell lymphoma (ALCL) and lymphomatoid papulomatosis (LyP). Numerous reports also identified variable CD30 expression in other lymphoproliferative disorders, such as PTCL, MF, SS, ATCLL or ENKTL [59-65]. Due to the limited CD30 expression on normal cells and the relative overexpression in certain tumor types, CD30 represents an important target for the immunotherapy of hematological malignancies.

Brentuximab vedotin is an antibody-drug conjugate (ADC) combining CD30 mAb with the microtubule inhibitor monomethylauristatin E. After ligation of ADC with CD30 on the surface of cancer cells, monomethylauristatin $\mathrm{E}$ binds to tubulin and disrupts the microtubule network in the cell, resulting in cell cycle arrest and apoptosis [66, 67]. Brentuximab vedotin has three main advantages. It can distinguish between normal and malignant cells and, therefore, has less toxicity in vivo. What's more, due to monomethylauristatin $\mathrm{E}$ conjugation to the $\mathrm{mAb}$, it remains relatively stable in the circulation, resulting in higher cytotoxicity. Finally, monomethylauristatin E released to the tumor microenvironment can kill surrounding non-targeted CD30 + malignant cells as well as non-malignant cells that may have protumor effects [68]. Brentuximab vedotin has so far been approved for the treatment of CD30+lymphoproliferative disorders such as classical Hodgkin lymphoma, systemic and primary cutaneous ALCL, MF, AITL and PTCL $=$ NOS.

Recently, phase-3 trial ECHELON-2 (NCT01777152) concerning the use of brentuximab vedotin in previously untreated $\mathrm{CD} 30+$ patients with PTCL has been initiated [69]. ECHELON-2 trial was conducted to compare the efficacy and safety of the chemotherapy regimen of CHOP (cyclophosphamide, doxorubicin, vincristine and prednisone) versus a combination of $\mathrm{CHOP}$ together with brentuximab vedotin $(\mathrm{A}+\mathrm{CHP})$. The results showed that the addition of brentuximab vedotin to $\mathrm{CHP}$ resulted in higher rates of PFS and overall survival (OS) of patients with median PFS of 48.2 months in comparison with 20.8 months in the CHOP group $(\mathrm{p}=0.011)$. What's more, the addition of brentuximab vedotin did not change the incidence and severity of adverse events such as febrile neutropenia (18\% of patients in the $\mathrm{A}+\mathrm{CHP}$ group and $15 \%$ in the $\mathrm{CHOP}$ group) and peripheral neuropathy $(52 \%$ in the $\mathrm{A}+\mathrm{CHP}$ group and $55 \%$ in the CHOP group). Therefore, ECHELON-2 trial results are considered to be potentially practice-changing and indicate the potential use of $\mathrm{A}+\mathrm{CHP}$ treatment in CD30+ PTCL patients. 


\section{Mogamulizumab-anti-CCR4 ab}

$\mathrm{C}-\mathrm{C}$ motif chemokine receptor 4 (CCR4) is a seventransmembrane G-protein-coupled receptor expressed on Tregs, type 2 helper $\mathrm{T}$ cells (Th2), memory $\mathrm{T}$ cells and cutaneous lymphocyte antigen-positive skin-homing $\mathrm{T}$ cells [70]. CCR4 expression present on Th2 and Tregs induces homing of these leukocytes to sites of inflammation. Tregs play a crucial role in maintaining immune balance; however, in malignancies, Tregs attenuate the host's anti-tumor immunity and provide a favorable environment for tumor growth [71]. Elevated CCR4 expression was also reported in patients with aggressive PTCL, especially in ATLL or CTCL; therefore, CCR4 seems to be a promising therapeutic target for $\mathrm{T}$ cell malignancies [72].

Mogamulizumab-kpkc is a mAb directed against the CCR4 receptor, which increases antibody-dependent cellular cytotoxicity (ADCC) in CCR4+malignant $\mathrm{T}$ cells. In addition to directly targeting malignant $T$ cells, mogamulizumab depletes CCR4+ Tregs, which is an important therapeutic target in many human malignancies due to their role in suppressing the host anti-tumor immunity [73]. In 2018, the FDA-approved mogamulizumab-kpkc was approved in 2018 by FDA for the treatment of refractory MF and SS after at least one prior systemic therapy.

\section{mAb in clinical trials}

\section{Anti-KIR3DL2 (CD158k) ab-IPH4102}

KIR3DL2, also known as CD158k, belongs to the family of killer cell immunoglobulin-like receptors (KIRs) normally detected on a minor NK cell subset and on rare $\mathrm{CD} 3+\mathrm{CD} 8+\mathrm{T}$ cells. Although it was shown that KIR3DL2 ligation on NK cells inhibits their production of IFN- $\gamma$ and cytotoxic function, KIR3DL2 function on $\mathrm{T}$ cells is less clear [74]. To date, numerous studies have identified elevated KIR2DL2 expression in transformed MF, pcALCL and SS [75-78]. In Sézary patients, KIR3DL2 was shown to act as an inhibitory co-receptor that promotes resistance to activation-induced cell death by its ability to down-modulate CD3-dependent early signaling events [79]. In addition, as the percentage of KIR3DL2 + peripheral mononuclear cells strongly correlates with the percentage of atypical circulating SS cells, KIR3DL2 is considered to be a diagnostic and prognostic marker for this disease [80]. Due to the limited expression of KIR3DL2 on normal immune cells and its high expression on malignant $\mathrm{T}$ cells, novel anti-KIR3DL2 therapeutic strategies have been proposed.

IPH4102 is an anti-KIR3DL2 mAb that was shown to deplete KIR3DL2 + cells through antibody-dependent phagocytosis and cell cytotoxicity [81]. The anti-tumor activity of IPH4102 was firstly shown in mouse xenograft models and further confirmed in an ex vivo model using the primary cells of SS patients, where it reduced tumor growth and improved cell survival. Those encouraging preliminary data resulted in a phase-I study in patients with relapsed or refractory CTCL, especially those with SS (NCT02593045) [82]. IPH4102 was associated with a favorable safety profile, high frequency of sustained global response and improvement of life quality, with peripheral edema and fatigue as the most common adverse effects. Overall response was achieved in 16 of 44 patients (36.4\%), and of those, 15 were observed in 35 patients with SS (43\%). Currently, phase II of IPH4102 is ongoing to confirm IPH4102 activity alone or in combination with chemotherapy in SS patients and other TCL subtypes that express KIR3DL2 (TELLOMAK, NCT03902184).

\section{Anti-CD38 ab-daratumumab}

CD38 is a type-II multifunctional transmembrane glycoprotein, with both ectoenzymatic and receptor functions, that can be found on the surface of terminally differentiated plasma cells, as well as T cells, NK cells and on myeloid cells at different stages of development [83, 84]. Its expression was reported in NK/T cell lymphomas and recently in AITL and PTCL-NOS $[85,86]$. Because of its function in the regulation and immunomodulation of metabolic pathways and also abnormal expression in hematologic malignancies that correlate with cell proliferation and disease progression, CD38 seems to be an attractive target for antibody-based therapies [83].

Daratumumab is the first-class $\mathrm{mAb}$ to target CD38 + myeloid-derived suppressor cells (MDSC) and regulatory $\mathrm{T}$ cells currently approved as a therapy for MM [87, 88]. Daratumumab targets CD38 causing tumor cell death through such mechanisms as antibodydependent cellular phagocytosis (ADCP) or antibodydependent cell-mediated cytotoxicity (ADCC) [89, 90]. After the promising outcome of the phase-II study (NCT02927925) involving daratumumab treatment in relapsed or refractory natural killer/T cell lymphomas with overall response rate (ORR: 25\%, 8/32 patients), a new trial is currently ongoing [91]. A phase-II study is now underway to evaluate the efficacy of daratumumab in combination with gemcitabine, cisplatin and dexamethasone in patients with PTCL-NOS, AITL and other nodal lymphomas of $\mathrm{T}$ follicular helper cells (TFH cells) origin. In this study, refractory/relapsed patients were included, after at least one, but no more than two previous therapeutic approaches (NCT04251065).

\section{Anti-CD25 (IL-2Ra) ab_basiliximab and camidanlumab}

CD25 is an alpha subunit of interleukin-2 receptor (IL2R) expressed mainly on the surface of the mature $T$ cell membrane, triple-negative thymocytes, B cells and bone 
marrow pre-B cells [92]. In normal conditions, CD25 can induce the affinity of IL-2R and IL-2 as well as induce CD4 + CD25 + Treg proliferation and differentiation [93]. High level of CD25 was reported in many hematological malignancies, including AITL and ALCL [94]. It was shown that upregulated CD25 expression in T cells promotes lymphomagenesis and drug resistance. Furthermore, an elevated serum level of soluble IL-2 receptor $\alpha$ (IL-2R $\alpha$ ) in NKTCL patients was significantly correlated with response to treatment and survival rate [92, 95]. It is also hypothesized that $\mathrm{CD} 25$ can be present on leukemic stem cells and induce oncogenic signaling pathways [92].

Basiliximab is a chimeric $\mathrm{mAb}$ that binds the $\alpha$ chain of CD25, leading to the competitive inhibition of $\mathrm{T}$ cell proliferation and, as a consequence, the inhibition of $\mathrm{T}$ cell activation [96]. After a successful phase-I clinical trial using ${ }^{131}$ Iodine-labeled basiliximab that showed complete or partial responses in patients with CD25+lymphomas, follow-up trials are currently underway [97]. Yttrium Y 90 basiliximab together with standard combination chemotherapy (carmustine, cytarabine, etoposide, and melphalan (BEAM)) is currently being evaluated in a phase-I study in patients with mature TCL (NCT02342782). Due to the previous results indicating that an elevated level of CD25 correlates with chemotherapy resistance and that CD25-mediated resistance can be reversed by targeting CD25, in the phase-II study, a combination of chemotherapeutic pegaspargase and basiliximab is being investigated in the treatment of relapsed or refractory NK and $\mathrm{T}$ cell lymphomas (NCT04337593).

Another antibody-drug conjugate targeting CD25 currently under evaluation is camidanlumab tesirine (ADCT-301). This antibody is conjugated to cytotoxic pyrrolobenzodiazepine (PBD) dimer, which causes cell death upon cross-linking specific sites of the DNA and blocking DNA replication [98]. Recently, a phase-I trial examining the safety, tolerability and pharmacokinetics of ADCT-301 in patients with relapsed or refractory HL and NHL patients ended (NCT02432235) with the phase-II study is still ongoing (NCT04052997).

\section{Anti-CD47 ab-TTI-621 (SIRPaFc)}

CD47 (also known as the integrin-associated protein IAP) is a transmembrane protein that belongs to the immunoglobulin superfamily. CD47 binds to several different proteins, but especially to signal regulatory protein alpha (SIRP $\alpha)$. CD47-SIRP $\alpha$ interactions are involved in many cellular processes, including proliferation, apoptosis and immune response as well as the inhibition of macrophage phagocytosis, thereby allowing cancer cells to escape immune surveillance $[99,100]$. Overexpression of CD47 was reported in many hematologic malignancies, including CTCL, where it seems to be correlated with a more aggressive course and a worse clinical outcome $[101,102]$. Therapies inhibiting CD47-SIRP $\alpha$ interaction are expected to work in two ways: firstly, by activation of adaptive immunity, resulting in cytotoxic anti-tumor responses, and secondly, by activation of innate immunity, therefore promoting cancer cells destruction by macrophages [103].

TTI-621 (SIRPa-IgG1 Fc) is a novel immune checkpoint inhibitor that blocks CD47 and prevents it from delivering an inhibitory signal to macrophages, therefore allowing them to phagocytose malignant cells [102]. The phase-I trial of TTI-621 treatment provided a promising outcome for further studies. Out of nine patients with MF or SS, one achieved CR and five additional patients experienced decreases in tumor size and/or a decreased number of circulating Sézary cells (NCT02890368) [104]. Currently, another phase-I trial of TTI-621 alone or in combination with other anti-cancer drugs (rituximab or nivolumab), in subjects with relapsed or refractory hematologic malignancies and selected solid tumors, is ongoing (NCT02663518).

In addition, another anti-CD47 mAb drug phase-I study is being conducted to evaluate the safety, tolerability, and initial efficacy of IBI188 injection in patients with advanced malignant tumors and lymphomas (NCT03763149).

\section{Anti-ICOS (CD278) ab-MEDI-570}

Inducible T cell co-stimulator (ICOS, cluster of differentiation (CD278)) is a co-stimulatory molecule minimally expressed on naïve $\mathrm{T}$ cells and increasingly expressed on both activated $\mathrm{CD} 4+\mathrm{T}$ cells and follicular helper $\mathrm{T}$ cells. It is suspected that ICOS may play an important role in the production of IL-2, IL-4, IL-5, and IFN $\gamma$ from recently activated $T$ cells as well as contribute to $T$ celldependent B help in vivo [105]. While in healthy humans, expression of ICOS can be detected in $5-20 \%$ of circulating peripheral blood $\mathrm{CD} 4+\mathrm{T}$ cells, studies showed that ICOS expression increases in patients with autoimmune diseases and is connected to increased pro-inflammatory cytokines expression [106, 107]. In addition, high ICOS expression on Tregs-infiltrating tumors is supposed to be associated with a poor prognosis [108].

MEDI-570 is an IgG1k mAb that attaches to the ligandbinding domain of ICOS expressed on tumor-infiltrating $\mathrm{CD} 4+\mathrm{T}$ cells, therefore preventing the interaction between ICOS $+\mathrm{T}$ cells and plasmacytoid dendritic cells (pDCs). This interaction leads to Treg-mediated immune suppression inhibition and the enhancement of the cytotoxic T-lymphocyte (CTL)-mediated immune anti-tumor response [109].

MEDI-570 was initially designed as a therapy for autoimmune diseases. However, a currently ongoing 
phase-I study will evaluate the side effects and best dose of MEDI-570 in patients with PTCL follicular variant or AITL that relapsed or did not respond to previous treatment (NCT02520791).

\section{Anti-CD52 ab-alemtuzumab}

CD52, also known as CAMPATH-1 antigen, is a small glycoprotein expressed on the surface of mature lymphocytes, monocytes, and dendritic cells. The exact function of CD52 remains to be elucidated; however, it was shown that CD52 signal transduction leads to lymphocyte proliferation and production of TNF- $\alpha$, IFN $\gamma$, and IL-6 [110]. In addition, studies demonstrated that CD52 can act as a co-stimulatory molecule inducing regulatory $\mathrm{CD} 4+\mathrm{T}$ cells [111].

Alemtuzumab is a humanized anti-CD52 mAb that depletes $\mathrm{T}$ and $\mathrm{B}$ lymphocytes through mechanisms such as induction of apoptosis, antibody-dependent cellular cytotoxicity (ADCC), and complement-dependent cytotoxicity (CDC) of cells [112-117]. For now, alemtuzumab has been approved for the treatment of $\mathrm{B}$ cell chronic lymphocytic leukemia and relapsing forms of multiple sclerosis (MS). Alemtuzumab was previously proposed as a treatment for heavily pretreated and refractory PTCL, where, although achieving a promising overall response rate $(36 \%)$, the treatment was associated with significant hematologic toxicity and infectious complications [118]. Alemtuzumab also showed promising clinical outcome and an acceptable safety profile in patients with advanced MF and SS; however, therapy was also associated with such adverse effects as cytomegalovirus (CMV) reactivation, fatal mycobacterium pneumonia, or cardiac toxicity $[119,120]$. Trials were also conducted to study the effect of the combination of alemtuzumab and the chemotherapeutic regimen $\mathrm{CHOP}$ (cyclophosphamide, doxorubicin, vincristine, and prednisone) combination in order to improve the outcome of the treatment in PTCL and aggressive T and NK cell lymphomas; however, the addition of alemtuzumab increased the risk of infection and the toxicity of the treatment [121-123]. Attempts to improve alemtuzumab treatment outcomes are currently underway. A phase-II trial is now ongoing to determine the toxicity of alemtuzumab (Campath$1 \mathrm{H})$ in combination with etoposide, prednisone, vincristine, cyclophosphamide, and doxorubicin (EPOCH) chemotherapy in non-Hodgkin's T and NK cell lymphomas (NCT00069238). The follow-up phase-I trial is now investigating the safety, toxicity profile, and maximum tolerated dose of recombinant human interleukin 15 (IL-15) in combination with standard IV alemtuzumab treatment in relapsed chronic and acute ATLL patients (NCT02689453).

\section{Bispecific antibody targeting both CD30 and CD16A- AFM13}

CD16A, a low-affinity receptor for the IgG Fc domain, belongs to the group of transmembrane proteins expressed on NK cells, macrophages, and mast cells. Upon ligation, CD16A is responsible for inducing the lysis of target cells by NK cells and ADCC [124, 125].

AFM13 is a bispecific, tetravalent chimeric antibody construct that specifically binds to CD30, found on the cancerous cells and CD16A on NK cells and macrophages. AFM13 induces NK cell-mediated and T cellmediated cytotoxicity and, as a consequence, tumor cell lysis [126]. AFM13 was first examined in a phase-I study of patients with relapsed or refractory Hodgkin lymphoma and demonstrated promising clinical and pharmacodynamic activity (NCT01221571). The treatment with AFM13 was well tolerated, with fever and chills being the most frequent adverse effects. Out of 26 patients included in the study, $11.5 \%$ achieved partial remission and 50\% achieved stable disease [126]. Recently, a phase-Ib/IIa trial was completed evaluating the biologic activity of AFM13 in patients with relapsed or refractory CD30+CTCL patients (NCT03192202). Preliminary results of the first three dose cohorts demonstrated that AFM13 showed promising therapeutic activity as a single agent, with an objective response rate (ORR) of 50\% (4/8 patients). Currently, there are two ongoing clinical trials. The first one, a phase-I study, is now examining the side effects and the best dose of AFM13 as monotherapy or modified umbilical cord NK cells combined with AFM13 in patients with $\mathrm{CD} 30+$ recurrent/ refractory Hodgkin lymphoma or non-Hodgkin treatment (NCT04074746). The second one is a phase-II trial to evaluate the antitumor activity and safety of AFM13 in patients with CD30 + PTCL or tMF (NCT04101331).

\section{Anti-CADM1 ab}

Cell adhesion molecule 1 (CADM1/TSLC1) is normally involved in cell adhesion, proliferation, and differentiation [127]. CADM1 is a well-known tumor-suppressor gene in human malignancies such as liver, prostate, or pancreatic cancer [128]. However, studies showed that in the case of ATL patients, CADM1 overexpression is involved in the attachment of ATL cells to vascular endothelial cells and therefore plays a role in oncogenesis [129]. CADM1 expression was also associated with tumor growth and organ infiltration of ATL cells [130]. Therefore, is seems that CAMD1 function in malignancies depends on the origin of the cell in which it is expressed. CADM1 was reported as being a diagnostic marker for ATL; however, a recent study suggests that 
it can also be useful for differentiating between MF and inflammatory skin disorders $[131,132]$.

A recent study investigated the potential of antiCADM1 antibodies in ATLL in a mouse xenograft model. Out of all examined antibodies, one clone, 103-189, showed weak but significant antibody-dependent cellular cytotoxic activity and effectively inhibited the interaction between endothelial cells and CADM1-positive ATLL cells. In addition, treatment with the 103-189 clone remarkably suppressed the organ invasion of mouse $\mathrm{T}$ cell lymphoma CADM1-positive cells in a mouse xenograft model, resulting in an improved survival rate of mice [133]. Results from this preliminary study suggest that further studies should be implemented to investigate the efficacy of a combination of anti-CADM1 antibodies and chemotherapy drugs in the treatment of ATLL.

\section{Chimeric antigen receptor $\mathrm{T}$ cells (carts) immunotherapy}

CAR molecules are created by combining the variable regions (Fv) of an antibody with the constant regions of the $\mathrm{T}$ cell receptor (TCR) chains. These molecules may be grafted into immune cells to create a tumor-specific treatment. The process of creating such a biologic drug requires choosing the proper target antigen, obtaining the cells from patients or cell line, transduction, culture expansion and infusing a sufficient number of effective and cancer-specific CAR-T cells (CARTs) or CAR-NK cells (CARNKs). The therapeutic mechanism is based on two natural functions of TCRs: antigen-binding and $\mathrm{T}$ cell activating [134, 135]. Cellular engineering and culturing of autologous patient $\mathrm{T}$ lymphocytes for their infusion have brought about a durable clinical response in cancers that had been treatment refractory by this time [136]. The use of modified immune cells encounters some natural obstacles, resulting from pathways that cancer cells use to avoid an immune response. They include inhibition of immune checkpoints (e.g., production of programmed cell death ligand 1 (PD-L1), changes in G1-regulating protein expression and changes in the metabolic environment through the secretion of suppressor factors like interleukin-10 (IL-10) and recruiting regulatory $\mathrm{T}$ cells). There are some strategies to revert the exhaustion of CAR-Ts, like replacement, reprogramming, and restoration of senescent cells [137].

Another issue encountered is the management of CARTs toxicities, of which the most serious are cytokine release syndrome (CRS) and neurologic toxicity, though the end-organ and hematologic toxicities are in most cases reversible [138]. CART therapy has proven to be effective in the treatment of $\mathrm{B}$ cell malignancies; therefore, a similar approach for treating $\mathrm{T}$ cell lymphomas seems to be natural next step. Finding a proper target antigen is challenging as most of them are the same for malignant and normal cells. Other important problems are fratricide and purity of harvested autologous $\mathrm{T}$ lymphocytes, as both malignancy and CART product recruit from the same cell population [139].

\section{CARTs in preclinical and clinical trials Anti-CD7 CARTs}

CD7 expression is limited to $T$ cells and starts appearing in the early state of lymphocyte differentiation, which makes it a great target for the treatment of $\mathrm{T}$ cell malignancies. It is highly expressed not only on the T-ALL blasts and about $30 \%$ of AML blasts but also in most normal $\mathrm{T}$ cells. CD7 CART are targeted by themselves as they also express $\mathrm{CD} 7$ antigens. This antigen may be removed from $\mathrm{T}$ cells without jeopardizing its immunocompetence. Png et al. applied a new approach to this problem by using a protein expression blocker (PEBL) based on an anti-CD7 single-chain variable fragment coupled with an intracellular retention domain. This was found to be an easy and effective way to obtain virtually instant abrogation of CD7 expression and to avert the fratricide effect. Cell lines and patient-derived xenograft (PDX) models have provided data confirming robust and specific cytotoxicity against investigated $\mathrm{T}$ cell malignancies, including ETP-ALL which is one of the most aggressive types. The authors suggest minimizing MRD before allogeneic hematopoietic stem cell transplantation, as the use of anti-CD7 cells, leads to the depletion of normal $\mathrm{T}$ lymphocytes and immunodeficiency [140]. Another way to manage the issue of sharing CD7 between CARTs and malignant cells was proposed by Cooper et al. They deleted CD7 along with the $\mathrm{T}$ cell receptor alpha chain (TRAC) using CRISPR/Cas9 and generated CARTs targeting CD7 (UCART7). Removal of TRAC blocks TCRmediated signaling, permitting the safe use of allogeneic $\mathrm{T}$ cells and allowing for the creation of an "off-the-shelf" product with no risk of contamination of autologous $\mathrm{T}$ lymphocytes with malignant cells. The cells obtained efficiently killed human T-ALL cell lines and patient-derived primary T-ALL in vitro and in vivo in the murine model, without resulting in xenogeneic GvHD [141]. Obtaining an adequate number of autologous $\mathrm{T}$ cells without malignant cell contamination is technically difficult. Therefore, You et al. have investigated the possibility of using the NK-92MI cell line to modify its TCR against the CD7 antigen. Cell lines and a mouse model were used in those experiments. The use of CAR-NK cells in the animal model has shown no significant toxicity, but a reduction in tumor burden and tumor growth was followed by significant survival prolongation. Compared with CAR-T cells, CAR-NK cells demonstrate three main advantages: direct killing of cancer cells by toxic granules, smaller 
cytokine release which brings a lower risk of CRS, and, last but not least, the possibility of "off-the-shelf' product development [135].

\section{Anti-CD4 CARTs}

Because CD4 is expressed on helper T lymphocytes and CD4-positive malignancies, a preclinical study on NSG mice with T-ALL tumors was conducted to investigate the possibility of using CARTs directed against this antigen [142]. The study showed a longer survival time and about $80 \%$ more effective tumor reduction in comparison with naïve T cells treatment. Alemtuzumab was used and proved to be efficient as a safety mechanism to eliminate CARTs after treatment. Following these results, clinical studies were planned. Currently, 3 recruiting clinical phase-I studies are investigating the clinical response, safety, and pharmacokinetics of using CD4-specific CARTs in patients with CD4+ T cell leukemias/lymphomas (NCT04162340, NCT04219319, NCT03829540). Because CARTs express CD4 themselves, similar to targeting CD7, NK-92 cells were tested in vitro and in vivo in a mouse model to kill CD4-positive malignant cells [143]. In vitro PTCL cell lines derived from both adult and pediatric primary cells were sensitive to CD4-CARNK treatment. A xenograft mouse model also showed that anti-CD4 CAR-NK cells were more effective compared with vector control NK-92.

\section{Anti-CD5 CARTs}

CD5 is a negative TCR regulator present not only on normal $\mathrm{T}$ lymphocytes and thymocytes but also on T-ALL and many PTCL subtype cells. Raikar et al. have tested NK-cell and CD5-depleted Jurkat $\mathrm{T}$ cell lines as CAR carriers in the treatment of $\mathrm{T}$ cell malignancies in vitro and in a xenograft $\mathrm{T}$ cell leukemia mice model [144]. Both strategies were found to be effective. The lack of significant immunosuppression and the in vitro/in vivo efficacy of anti-CD5 CARTs/CARNKs open the gate to investigating further possibilities regarding the adoption of cell therapy utilizing this antigen for $\mathrm{T}$ cell leukemias and lymphomas. A phase-I clinical trial took this approach to 10 patients with $\mathrm{T}$ cell malignancies expressing CD5 on at least $50 \%$ of malignant cells. Nine patients were evaluated; a response was noted in 4 and CRS in 3 of them [145].

\section{Anti-CD30 CARTs}

CD30 is a transmembrane receptor and a member of the tumor necrosis factor (TNF) receptor superfamily. It is expressed on a small subset of activated normal (nonmalignant) lymphocytes and is a common surface molecule for ALCL. It is also expressed in a subset of MF, PTCL, and ATLL [54]. However, the risk of premature elimination of $\mathrm{T}$ or $\mathrm{B}$ cells during virus responses was taken into consideration, though in an ex vivo study, the anti-CD30 CAR-T cells did not impair cellular immune responses [146, 147]. This suggests that the expression of the CD30 molecule on the memory T cells is not sufficient for being recognized and killed by anti-CD30 CARTs [148].

CD30 expression on hematopoietic stem and progenitor cells (HSPCs) during activation may lead to disorders of hematopoiesis including bone marrow aplasia. However, HSPCs compared to CTCL cells show resistance against CAR-Ts-driven lysis and when co-cultured with anti-CD30 CAR-Ts formed almost normal myeloid colony formation $[149,150]$. Moreover, in humanized mice during HSPCs reconstitution autologous CD30-directed CAR-T cells do not impair human peripheral $\mathrm{T}$ and $\mathrm{B}$ cells, which allows us to presume low bone marrow toxicity of anti-CD30 CAR-Ts [150].

The presence of increased levels of soluble CD30 in the plasma of patients with HL and ALCL could raise concerns about competitive CAR binding; however, in vitro studies demonstrated that it did not negatively impact the activity of anti-CD30 CAR-Ts [146, 150].

\section{Anti-TCR}

Targeting TCR itself seems to also be a promising approach. Beta-chain regions are coded by two different genes, TRBC1 and TRBC2. In healthy adults, T cells express one of the two in about equal numbers but malignancy develops from only one type [149]. In this situation, targeting one of them would keep the other population intact, thereby ensuring the proper immunity of patients and preventing the fratricide of CARTs. TRBC1- or TRBC2-targeting CARTs are in preclinical studies [151] and in phase-I/II ongoing clinical trials in patients with relapsed or refractory TRBC1 positive TCL (AUTO4) (NCT03590574).

\section{Other approaches}

Immunotoxins

Immunotoxins are hybrid molecules containing a biologic toxin chemically conjugated to monoclonal antibody, cytokine, or growth factor that binds specifically to target cells [152]. Immunotoxins are predicted to be more efficient than $\mathrm{mAb}$ in target tissues such as bone marrow and skin, where $\mathrm{mAb}$ have poor therapeutic functions due to a lack of accessory cells from the innate immune system to initiate antibody-dependent cellular phagocytosis, antibody-dependent cellular cytotoxicity, or complement-dependent cytotoxicity [153]. To date, the FDA has approved only one immunotoxin for the treatment of $\mathrm{T}$ cell hematologic malignancy. With overall response rates between 30 and 50\%, denileukin diftitox 
(anti-CD25; Ontak ${ }^{\circledR}$ ) was approved in 1999 for the treatment of persistent or relapsed CD25-positive CTCL [154, 155]. The drug was used until 2014, when, due to production issues related to E. coli expression and purification, its marketing was discontinued. Denileukin diftitox was composed of two components: a full-length sequence of IL-2, which could bind to the IL-2 receptor on T cells, and a modified cytotoxic diphtheria toxin amino acid chain [156].

Recently, Wang et al. once more investigated the potential of IL2 fusion toxin. The group compared the efficacy of IL-2 fusion toxin with developed antihuman CCR4 immunotoxin (CCR4 IT) and demonstrated that CCR4 IT showed greater tumor response in a CD25+CCR4 + CTCL mouse model than IL-2 fusion toxin. What's more, the group constructed an IL2-CCR4 bispecific IT and showed that it was significantly more effective than either IL2 fusion toxin or CCR4 IT alone, therefore presenting a novel, promising targeted therapeutic drug candidate for the treatment of refractory and relapsed CTCL patients [153].

Currently, E7777, a new version of Ontak $^{\circledR}$ with improved purity and a high percentage of active monomer is being tested in patients with persistent or recurrent CTCL. In a phase-I study carried out in Japanese patients, E7777 showed an objective response rate of $38 \%$, with preliminary but clinically meaningful antitumor activity observed [157]. The phase-III clinical trial is now underway (NCT01871727).

\section{miR-155 inhibitor (cobomarsen)}

MicroRNAs (miRNAs) are small, 21-22-nucleotide (nt) noncoding RNAs that function as a posttranscriptional regulators of protein expression in normal and pathological cellular processes [158]. miR-155 plays a role in the immune response, lymphocyte development, function and differentiation [159, 160]. In addition, an elevated level of miR-155 is associated with genomic instability of malignant cells, sustained cell proliferation and survival [161]. Increased expression of miR-155 was shown in many solid tumors and hematological malignancies, including NKTCL and CTCL $[162,163]$. miR-155, a microRNA associated with poor prognosis in lymphoma and leukemia, has been implicated in the progression of MF [153], the most common form of CTCL.

Cobomarsen is a synthetic locked oligonucleotide inhibitor of miR-155 that was shown to inhibit cell proliferation and induce cell apoptosis in MF and HTLV-1 + CTCL cells [164]. Cobomarsen is currently being tested in three clinical trials. A phase-I study is being conducted to establish the safety, tolerability, pharmacokinetics, and potential efficacy of the tested drug in patients with certain lymphomas and leukemias, including CTCL (NCT02580552).

An ongoing phase-II trial is focused on comparing the effects of the efficacy and safety of cobomarsen to vorinostat, a drug that has already been approved for the treatment of CTCL (SOLAR, NCT03713320). Another phase-II study, which is a follow-up to the SOLAR study, focuses on patients who have confirmed disease progression following treatment with vorinostat and will reveal the tolerability and safety of cobomarsen based on the potential side effects (PRISM, NCT03837457).

\section{Phosphoinositide 3-kinase $\delta / \gamma$ inhibitors(pi3ki)}

Phosphatidylinositol 3-kinase (PI3K) is a lipid kinase involved in intracellular signal transduction. Four catalytic subunits of PI3K exist in human cells $(\alpha, \beta, \delta$, and $\gamma)$ [165]. The PI3K- $\delta$ and PI3K- $\gamma$ isoforms are preferentially expressed in leukocytes and extensively modulate both innate and adaptive immune function [166]. Multiple pathways mediated by PI3K- $\delta$ and/or PI3K- $\gamma$ contribute to the survival, proliferation, and differentiation of malignant hematopoietic cells through tumor cell-autonomous effects. At the same time, cancer cells can modulate the tumor microenvironment through juxta-, para-, and endocrine effects on non-malignant stromal and immune cells that involve PI3K signaling. Recent studies have suggested that PI3K- $\gamma$ may also suppress antitumor immune responses involving innate and adaptive effector cells [167]. PI3K- $\gamma$ signaling functions through C/EBP $\beta$ as a key inhibitor of phagocytosis by tumorassociated macrophages (TAMs). In this state, TAMs negatively regulate effector $\mathrm{T}$ and $\mathrm{NK}$ cells by secreting soluble immunosuppressive factors and expressing membrane-bound immune checkpoint molecules such as PD ligand 1 (PDL1). Selective inhibition of PI3K- $\gamma$ in solid tumor models can induce an immunostimulatory transcriptional program and M1 macrophage phenotype that restores $\mathrm{CD} 8+\mathrm{T}$ cell activation. Thus, there are at least 3 different mechanisms through which PI3K- $\delta, \gamma$ inhibition could be active against lymphoid malignancies. The first involves the blocking of mitogenic and survival signaling within the tumor cell (cell autonomous). The second involves the blocking of mitogenic and survival signaling induced by factors within the tumor microenvironment, including cytokines, chemokines, and juxtacrine interactions. Finally, inhibition of PI3K- $\delta$, PI3K- $\gamma$, or both together could activate anti-lymphoma immune responses.

\section{PI3Ki in clinical trials}

Duvelisib (IPI-145) is an oral, dual inhibitor of PI3K- $\delta$ and PI3K- $\gamma$ [168]. PI3K- $\delta / \gamma$ inhibition may directly inhibit malignant $\mathrm{T}$ cell growth, making duvelisib a promising 
candidate for patients with PTCL or CTCL. Inhibition of either isoform may also contribute to clinical responses by modulating non-malignant immune cells. These dual effects were investigated in a TCL cohort from a phase1 , open-label study of duvelisib in patients with relapsed or refractory PTCL $(n=16)$ and CTCL $(n=19)$, along with in vitro and in vivo models of TCL (NCT01476657) [169]. The overall response rates in patients with PTCL and CTCL were $50.0 \%$ and $31.6 \%$, respectively $(P=0.32)$. There were 3 complete responses, all among patients with PTCL. Activity was seen across a wide spectrum of subtypes. The most frequently observed grade 3 and 4 adverse events were transaminase increases ( $40 \%$ alanine aminotransferase, $17 \%$ aspartate aminotransferase), maculopapular rash (17\%), and neutropenia (17\%). In summary, duvelisib demonstrated promising clinical activity and an acceptable safety profile in relapsed/refractory TCL, as well as preclinical evidence of both tumor cellautonomous and immune-mediated effects.

Tenalisib (RP6530) is a novel, highly specific, dual $\mathrm{PI} 3 \mathrm{~K}-\delta / \gamma$ inhibitor with nano-molar potency. In the first phase-I, open-label study to evaluate the safety, pharmacokinetics, and efficacy of tenalisib in patients with relapsed/refractory hematologic malignancies, 35 patients were enrolled [170]. No dose-limiting toxicity was reported at any of the dose levels. The most common treatment-emergent adverse events irrespective of causality were asthenia and cough in $15(43 \%)$ patients and pyrexia in $13(37 \%)$ patients. The most frequently reported related treatment-emergent adverse events (TEAE) were diarrhea, nausea, and vomiting. Related grade $3 / 4$ adverse events were limited to events of hypertriglyceridemia, neutropenia, and diarrhea. Of 31 patients included in the efficacy analysis, a complete response was seen in $2(7 \%)$ patients and a partial response in 4 (13\%) patients, with an overall response rate of $19 \%$ and a disease-control rate of $61 \%$. The median duration of response was 5.7 months. Responders demonstrated a marked downregulation of phospho-AKT on C1D8. Tenalisib demonstrated acceptable safety up to $1200 \mathrm{mg}$ twice a day with no dose-limiting toxicities. A consistent clinical response was seen at doses of $200 \mathrm{mg}$ BID and above. Pharmacodynamics correlated well with clinical outcome. Further phase-I/II studies are being undertaken to evaluate efficacy across different histologies.

In a second study, histologically confirmed patients, with $\geq 1$ prior therapy, received tenalisib orally in a 28-day cycle in doses of 200 to $800 \mathrm{mg}$ twice daily in the escalation phase $(n=19)$ and $800 \mathrm{mg}$ twice daily in the expansion phase $(n=39)$ [171]. The most frequently reported TEAE and related TEAE were fatigue (45\%) and transaminase elevations (33\%), respectively. The most frequently reported related grade $\geq 3$ TEAE was transaminase elevation (21\%). Two dose-limiting toxicities occurred in the $800 \mathrm{mg}$ fed cohort; hence, an $800 \mathrm{mg}$ fasting dose was deemed MTD. Tenalisib was absorbed rapidly with a median half-life of $2.28 \mathrm{~h}$. ORR in 35 evaluable patients was $45.7 \%$ ( 3 CR and $13 \mathrm{PR}$ ), and the median duration of response was 4.9 months. Responding tumors showed a marked downregulation of CD30, IL-31, and IL-32 $\alpha$. With acceptable safety and promising clinical activity, tenalisib can be a potential therapeutic option for relapsed/refractory TCL. Currently, a phase-I/II combination study with romidepsin is ongoing (NCT03770000). The safety and efficacy data support the development of tenalisib as monotherapy or in combination with existing or novel targeted therapies in patients with hematological malignancies. Ongoing data from studies of tenalisib as monotherapy in indolent NHL (NCT03711578) and in combination with romidepsin in TCLs (NCT03770000) indicate that tenalisib is well tolerated. With a favorable safety profile and promising clinical activity, tenalisib holds promise as an emerging potential therapeutic option for patients with relapsed/ refractory TCL.

\section{Anaplastic lymphoma kinase inhibitors (Alki)}

Anaplastic lymphoma kinase (ALK) is a receptor tyrosine kinase belonging to the insulin receptor superfamily, sharing a high degree of homology with leukocyte tyrosine kinase (LTK) [172]. As a receptor tyrosine kinase of insulin receptor (IR) subfamily, anaplastic lymphoma kinase (ALK), has been validated to play important roles in various cancers, especially in non-small cell lung cancer (NSCLC) and anaplastic large cell lymphoma (ALCL). The presence of ALK fusion proteins and the constitutive ALK tyrosine kinase activity represent a therapeutic target in all malignancies with ALK rearrangement. Further, considering that ALK is not widely expressed in adult tissue, few toxic effects might be expected from treatment aimed at blocking ALK function. Currently, the FDA has approved five small-molecule inhibitors of ALK, including crizotinib, ceritinib, alectinib, brigatinib, and lorlatinib, against ALK + ALCL. Novel type-I1/2 and type-II ALK inhibitors with improved kinase selectivity and an enhanced capability to combat drug resistance have also been reported [173-175]. Moreover, the "proteolysis targeting chimera" (PROTAC) technique has been successfully applied in developing ALK degraders [176-178], which opened a new avenue for targeted ALK therapies.

\section{ALKi in clinical trials Crizotinib}

ALCL-inclusive trials and case series of ALCL patients treated with the first-generation ALK inhibitor crizotinib 
have yielded remarkably positive results, particularly in the pediatric population $[179,180]$.

In a study by the Children's Oncology Group (COG), 21 out of 26 pediatric patients exhibited a complete response to ALK inhibition using crizotinib as a frontline monotherapy [181]. Unfortunately, the discontinuation of crizotinib led to abrupt relapse of ALK-Positive lymphoma patients [182].

\section{Ceritinib}

A phase $1 \mathrm{~b}$ study of ceritinib was conducted in patients with ALK + ALCL (NCT01283516). The study showed that two of three ALK + ALCL patients treated at a dose of $750 \mathrm{mg} / \mathrm{d}$ achieved CR and 1 PR [183]. The responses were ongoing for all 3 patients, with durations of $>20$ months. Two patients experienced adverse events that required ceritinib dose reductions. A recently completed phase Ib study evaluating crizotinib in ALCL demonstrated an overall response rate of $53 \%$, with $47 \%$ of patients obtaining a complete remission [184].

Currently, several clinical trials are running on crizotinib, lorlatinib, and ceritinib (NCT03505554, NCT02419287, and NCT01979536) with promising preliminary results. Despite the preliminary successes reported for ALK kinase inhibition in ALK+ALCL, resistance mutations have been reported [185], decreasing the sensitivities of ALCL cells to various ALK inhibitors [186]. Therefore, a cocktail of ALK inhibitors, as compared to a single inhibitor, may prove to be most effective if used upfront to preempt selection for resistant clones that would lead to relapse.

\section{BCL11B inhibition}

$B$ cell lymphoma/leukemia 11B gene (BCL11B) encodes a Krüppel-like $\mathrm{C} 2 \mathrm{H} 2$-type zinc finger transcription factor playing an important role in $\mathrm{T}$ cell development. It has been shown by us and others that $B C L 11 B$ is overexpressed in $\mathrm{T}$ cell neoplasms [187, 188] and that suppression of BCL11B using siRNA leads to massive apoptosis of malignant $\mathrm{T}$ cells but not normal T lymphocytes [189]. The selective Bcl11b dependence of transformed $\mathrm{T}$ cells makes it an attractive target for novel therapeutic strategies directed against T-ALL and TCLs. Our group is currently running experiments in an inducible $B C L 11 B$ knock-out mouse model spontaneously developing T-ALL to determine the therapeutic effect of $B C L 11 B$ suppression. However, to date, a specific $B C L 11 B$ inhibitor has not been discovered.

\section{Antibiotic treatment}

Due to the progressive immunodeficiency and skin barrier breakdown, bacterial infections constitute a major clinical problem in patients with CTCLs. Indeed, potential infectious involvement in triggering or promoting CTCLs has long been suspected, with inconsistent results from many studies [190]. One of the pathogens proposed to play a role in CTCLs pathogenesis is Staphylococcus aureus, as its infection was connected to disease severity [191]. It was hypothesized that staphylococcal enterotoxins (SE) provide a persistent antigen stimulus for $\mathrm{T}$ lymphocytes resulting in the expansion of malignant $\mathrm{T}$ cells [192]. Additionally, it was shown that antibiotic treatment of S.aureus is associated with a clinical improvement in CTCL patients [193].

Recently, Lindahl et al. proposed a new therapeutic strategy for CTCL patients colonized by S.aureus [194]. A study showed the clinical benefits of shortterm, aggressive antibiotic therapy on disease activity in 8 patients with advanced-stage CTCL. Immunohistochemistry, global messenger RNA expression, and cellsignaling pathway analysis showed that antibiotic therapy resulted in decreased expression of IL-2 receptor CD25, STAT3 signaling, and cell proliferation in lesional skin. In addition, in the case of some patients, clinical improvement lasted for longer than 8 months, which proposes a novel therapeutic strategy for the treatment of advanced CTCLs.

Currently, two clinical trials are examining the efficacy of doxycycline antibiotic treatment alone or in combination with other drugs in CTCL patients. In the early phase-I study, a combined approach of doxycycline and imiquimod, a drug enhancing the host immune system to destroy cancer cells, is being investigated (NCT03116659). Additionally, a phase-II study is examining doxycycline monotherapy in patients with relapsed CTCL (NCT02341209). The results of completed and ongoing clinical trials of targeted therapies in T cell lymphomas are summarized in Tables 1 and 2, respectively.

\section{Conclusion}

In contrast to tremendous improvement in the treatment of B cell lymphomas, advances in $\mathrm{T}$ cell lymphomas have been hindered by the rarity of each individual subtype, an incomplete understanding of the pathophysiology, and a lack of large clinical trials. Recent fundamental insights into the pathophysiology of TCL have generated potentially ground-breaking therapeutic breakthroughs and resulted in numerous ongoing clinical trials with a variety of target-specific agents. Although therapeutic improvements in TCL, except ALK + ALCL, are not yet 


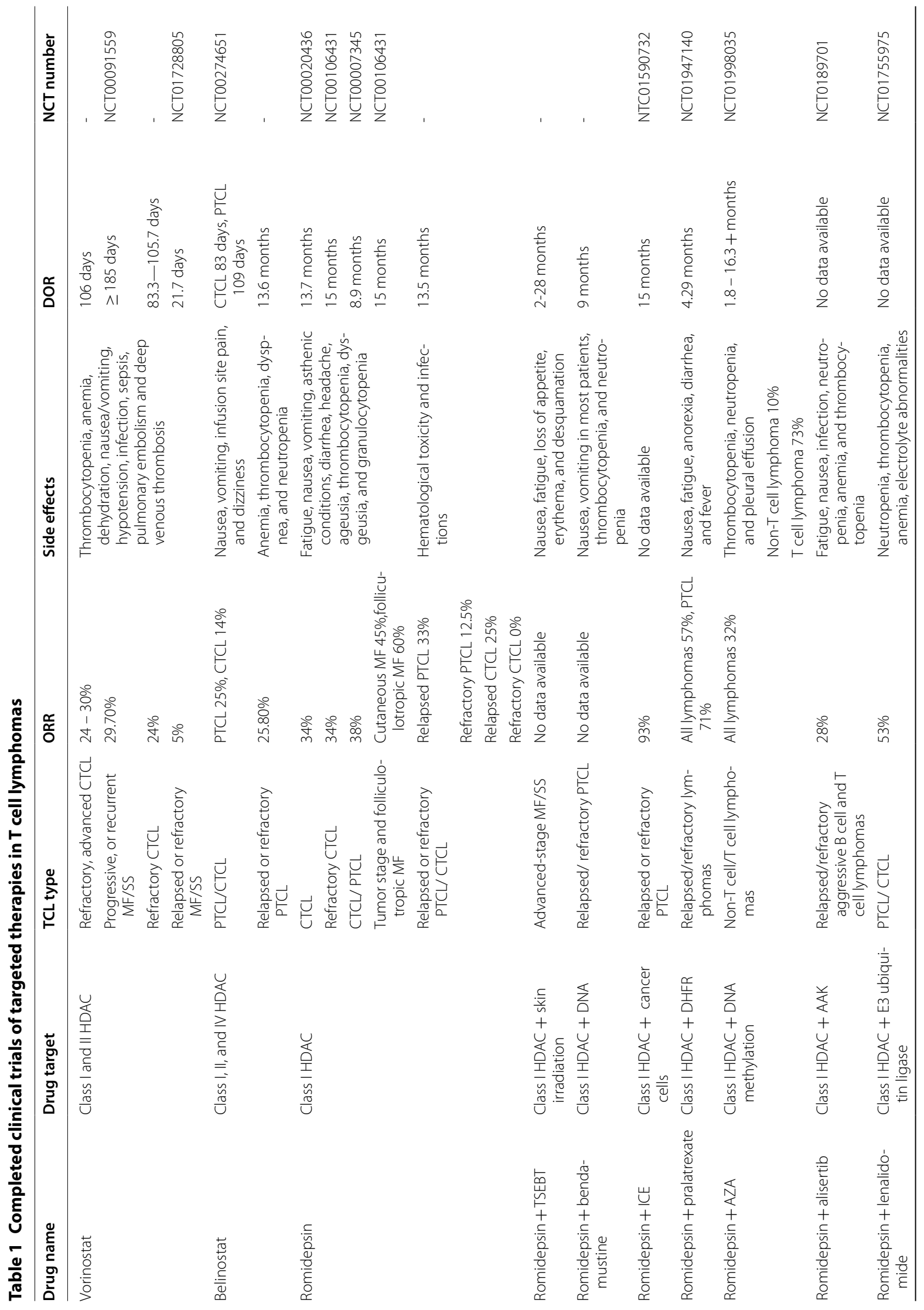




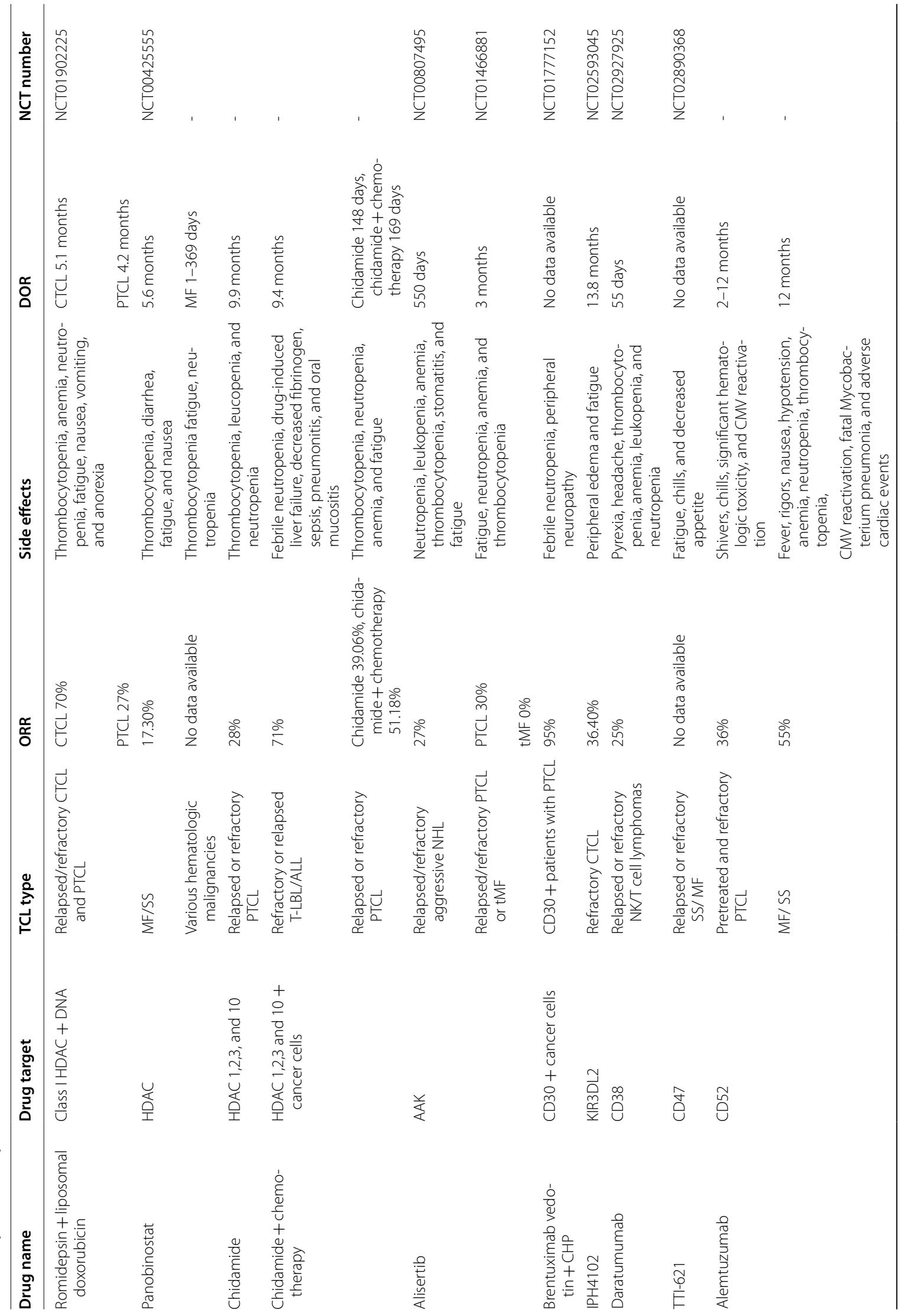




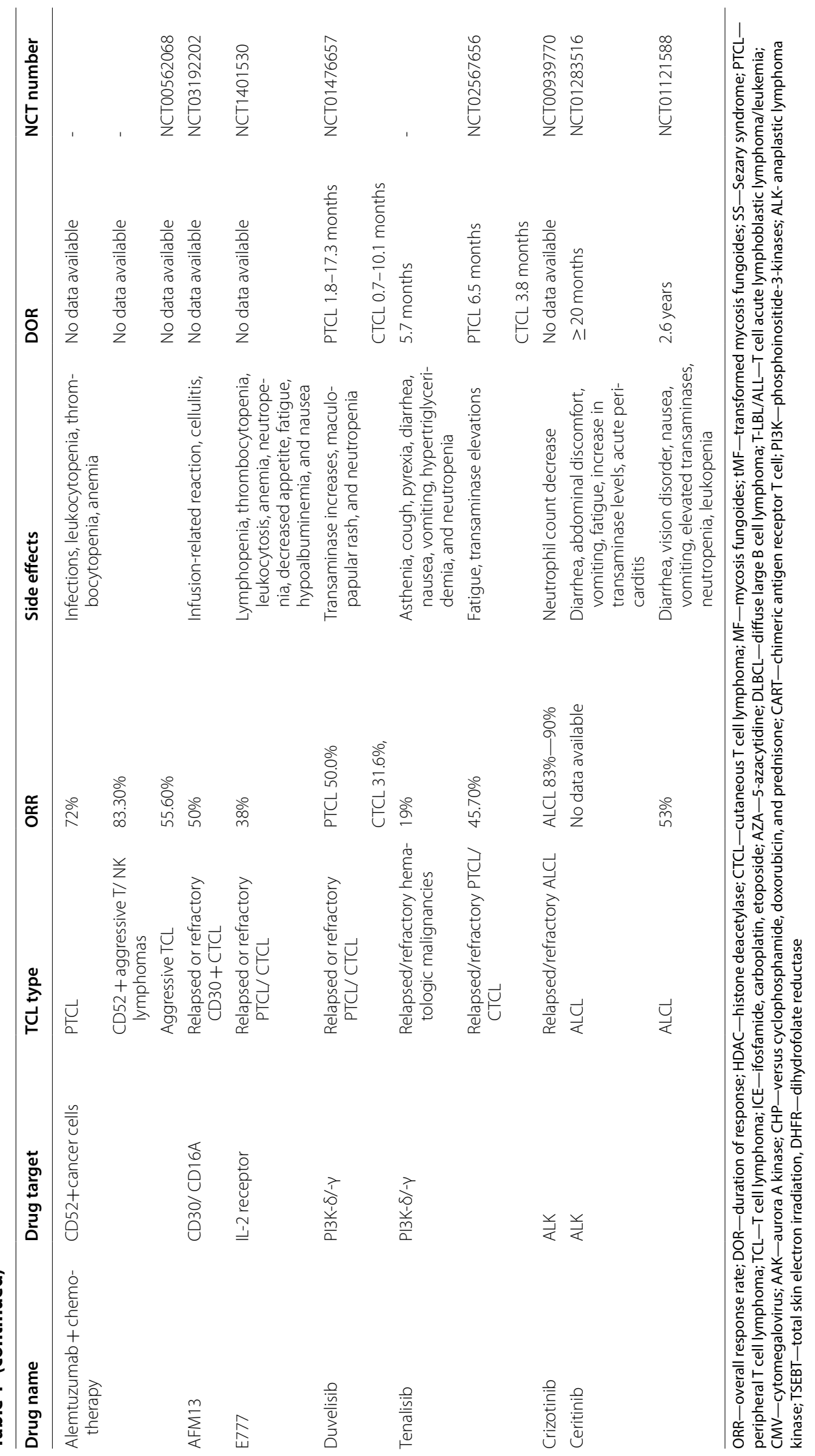




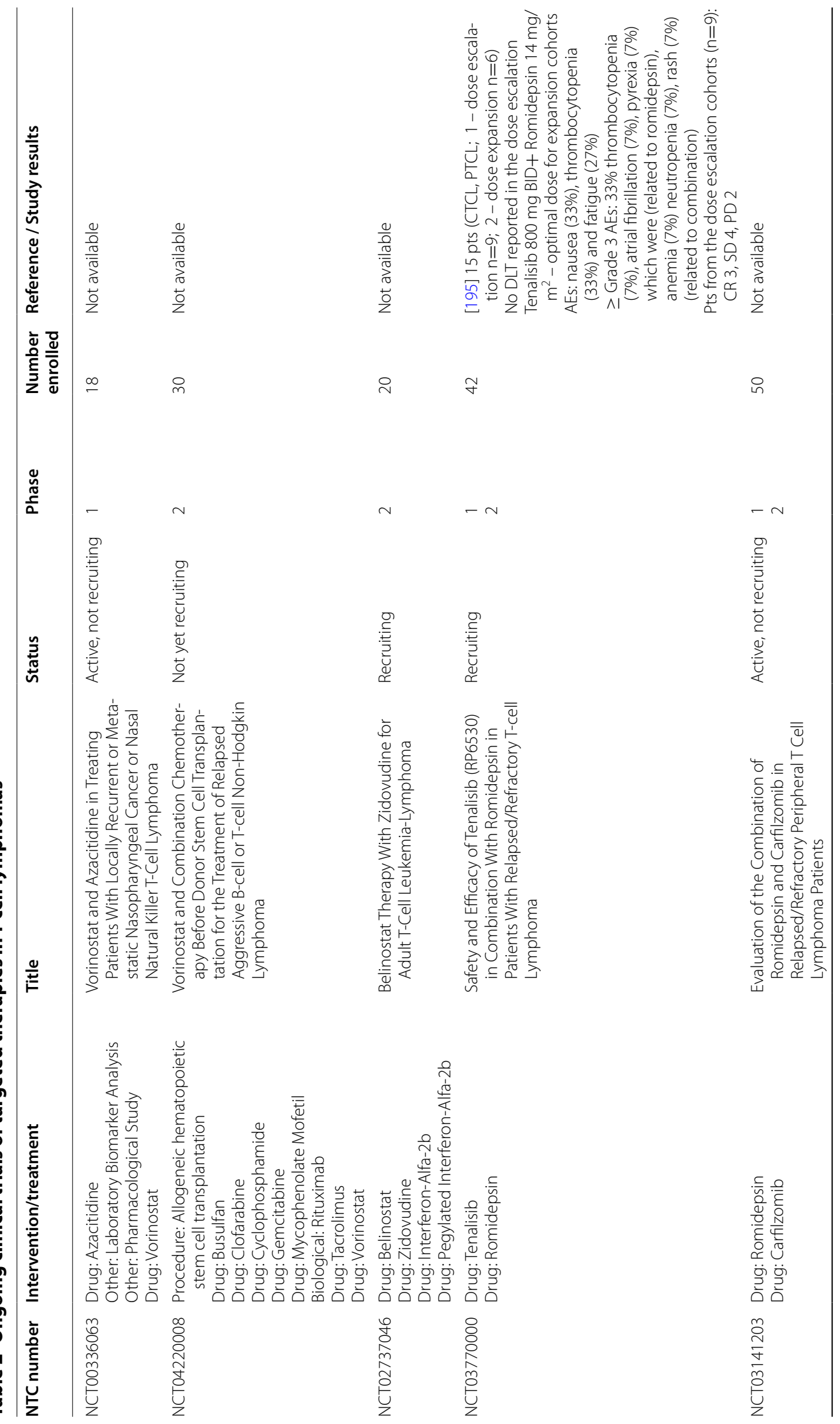




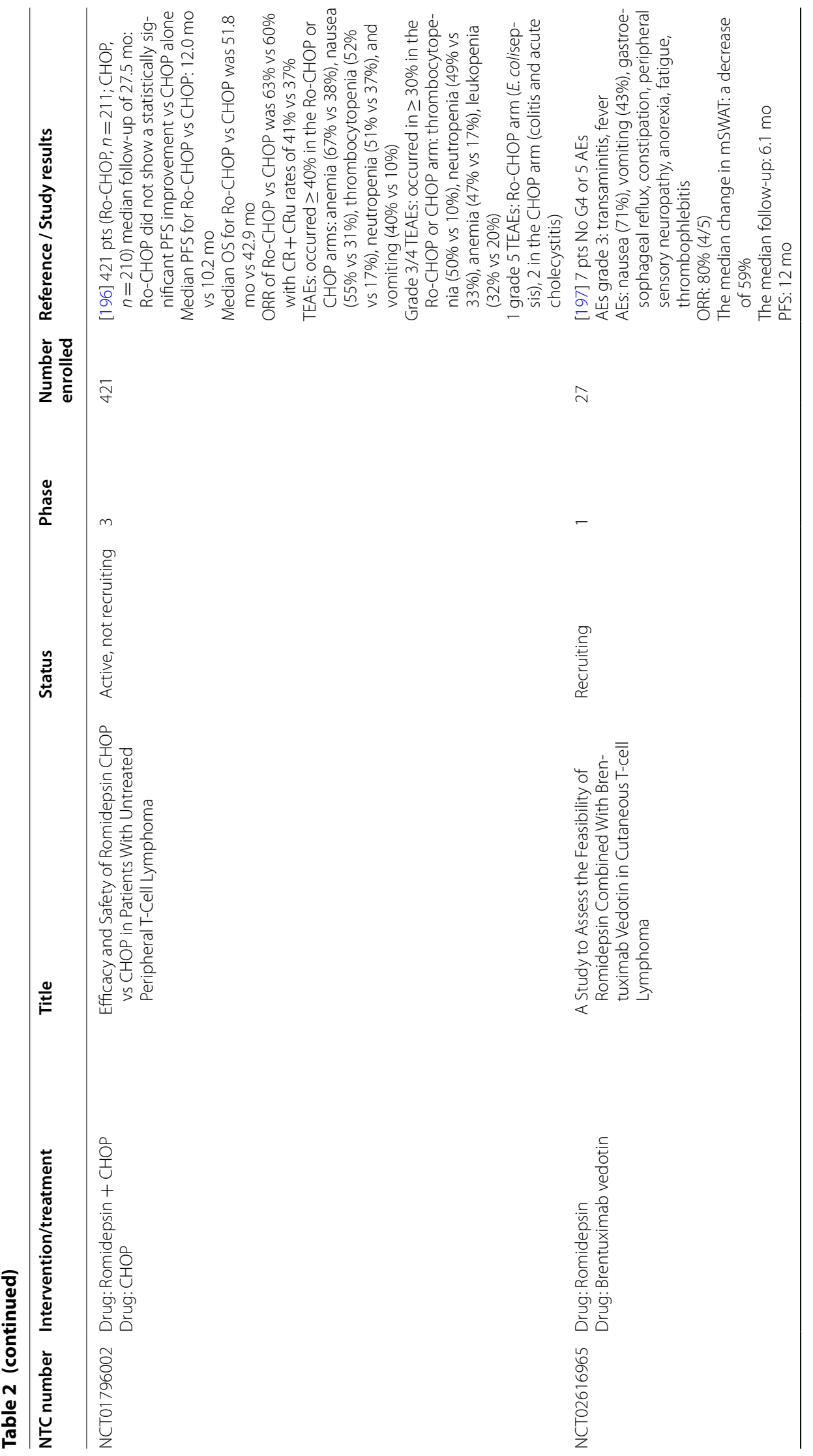




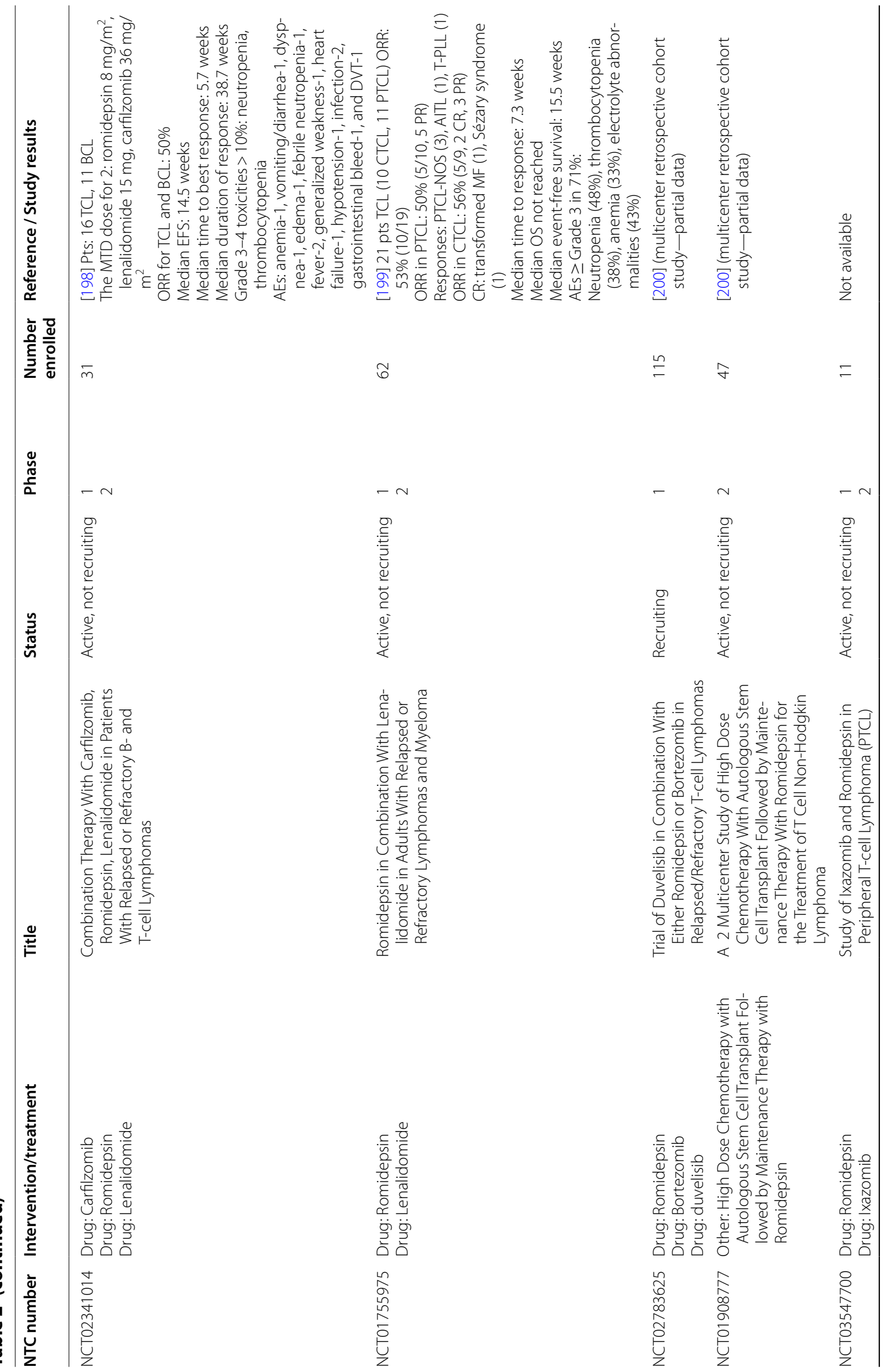




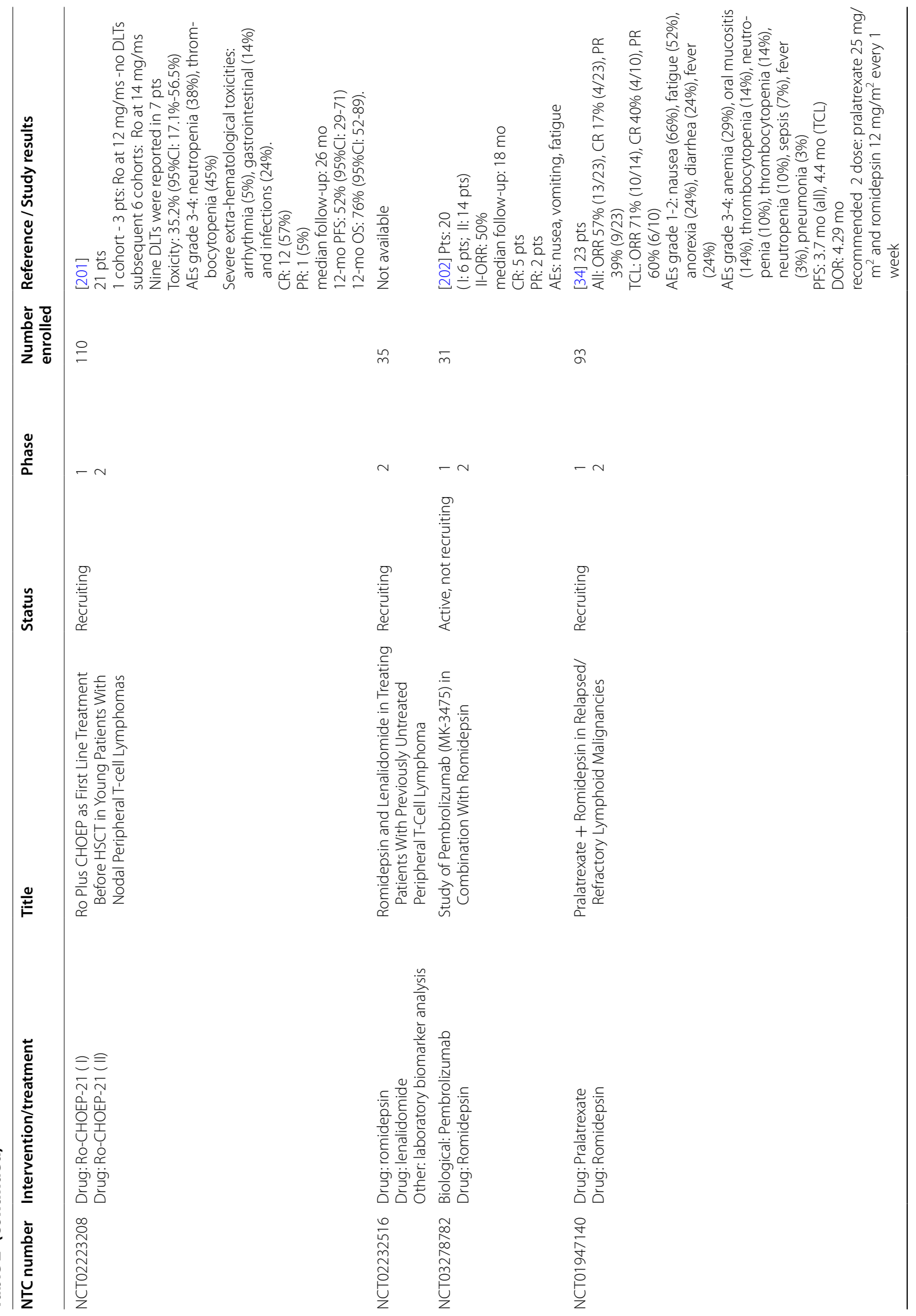




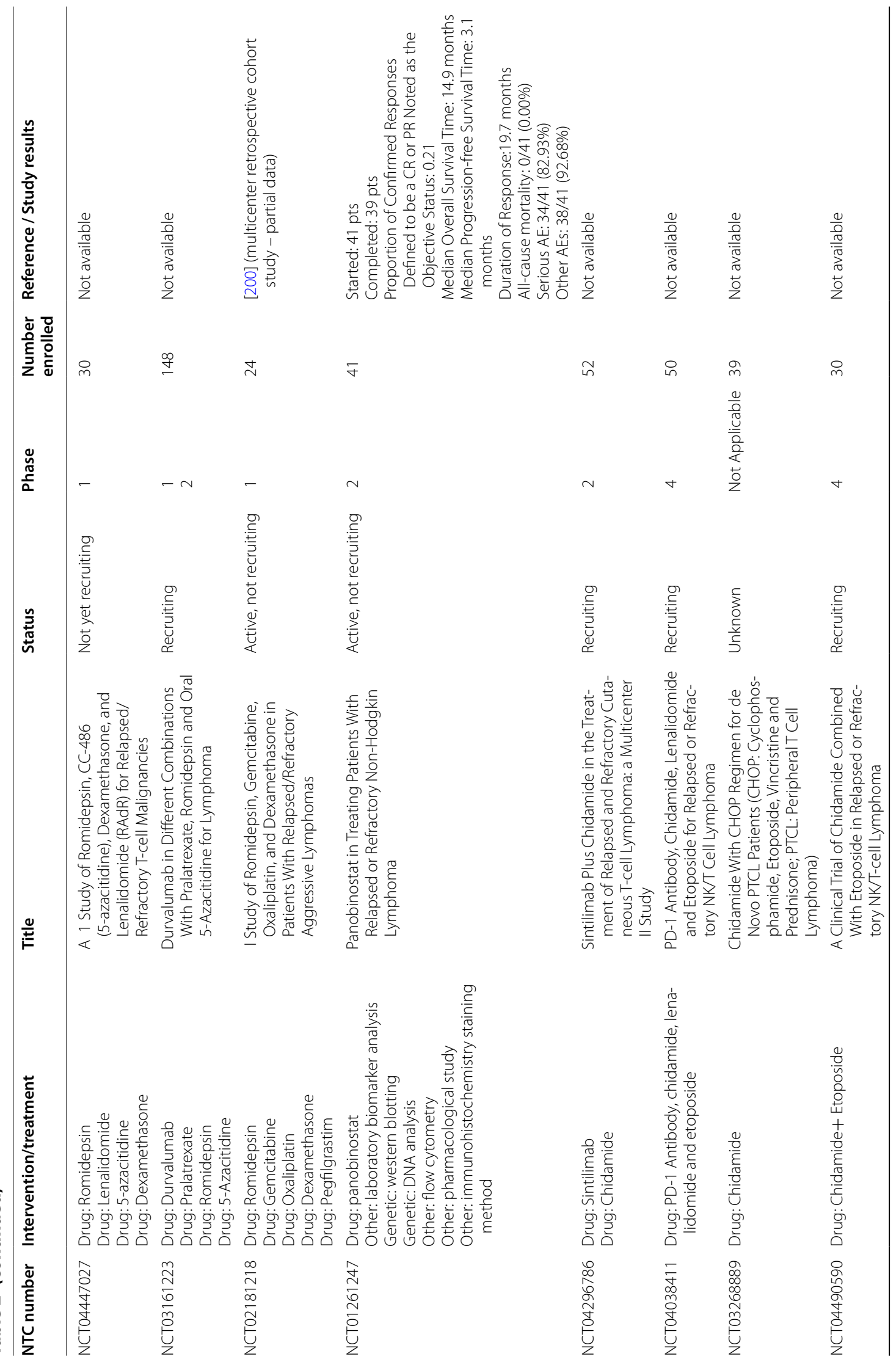




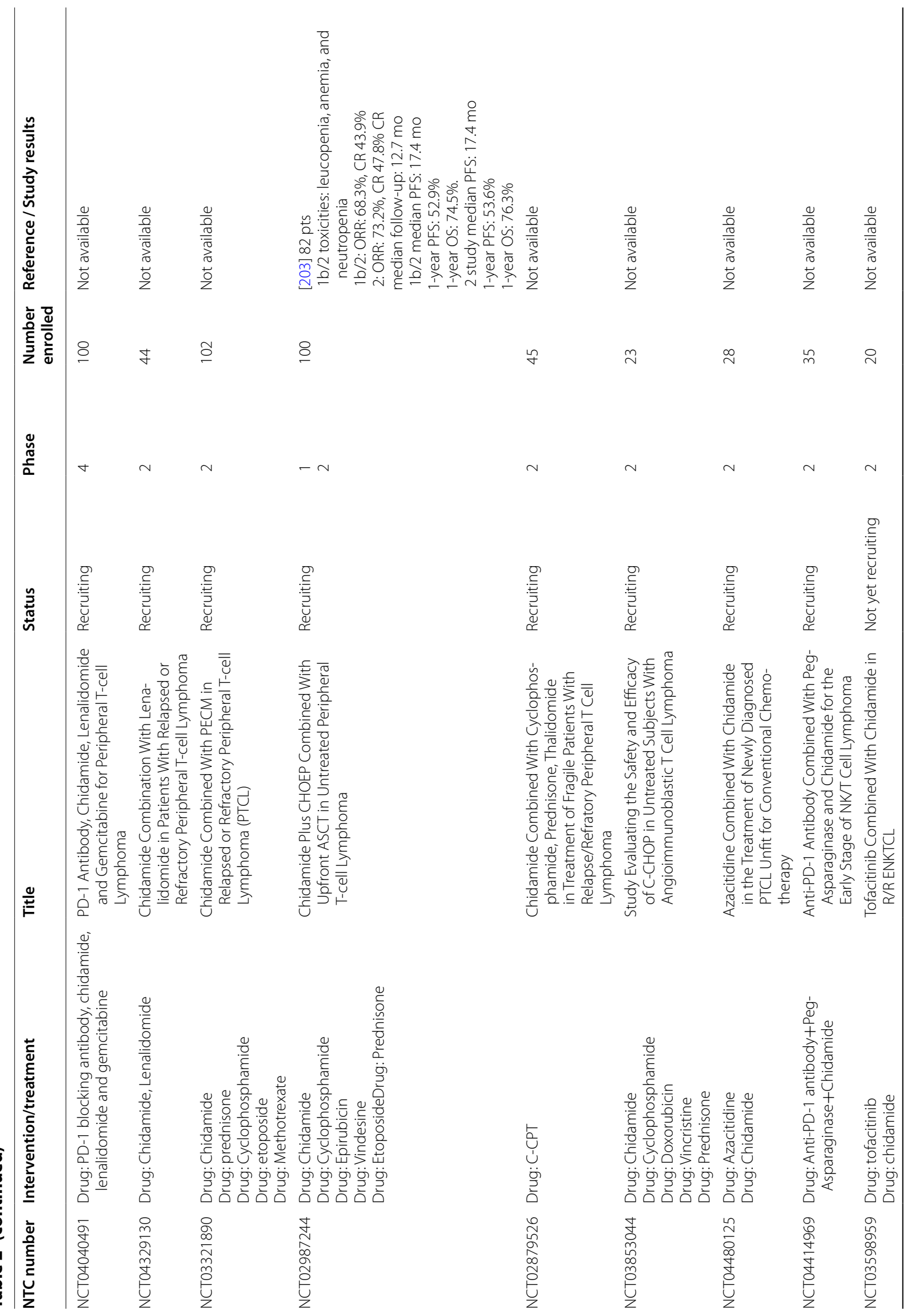




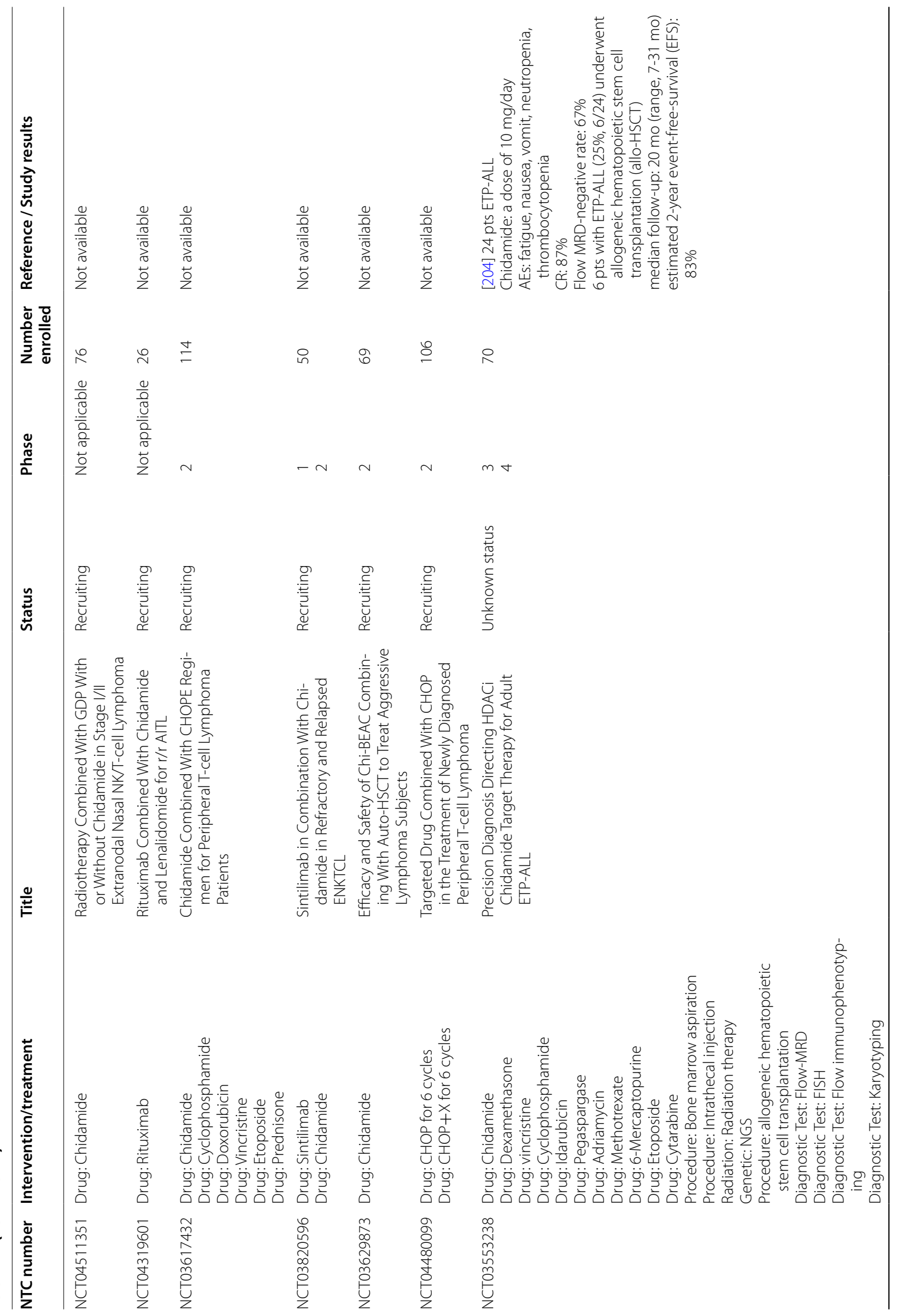




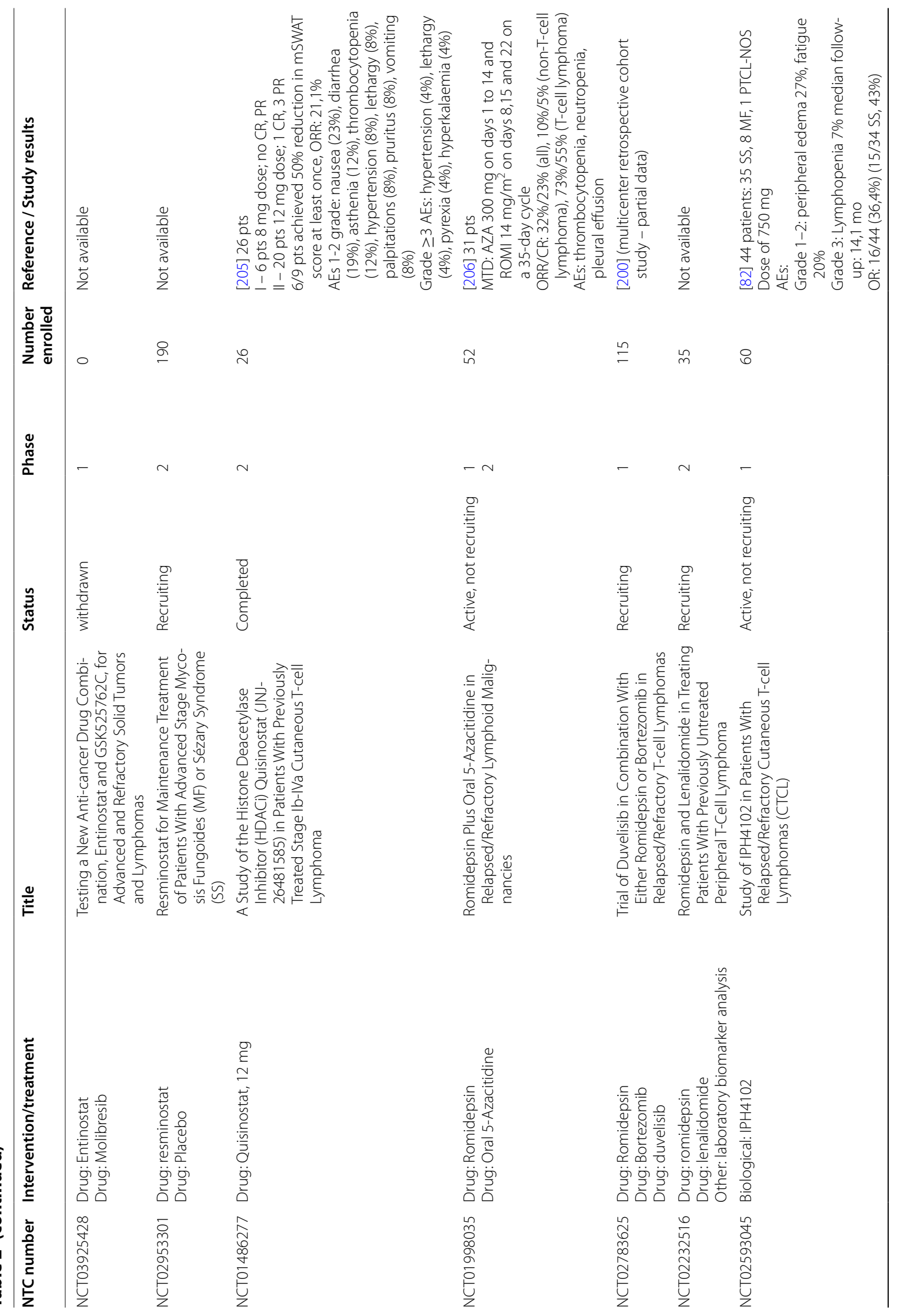




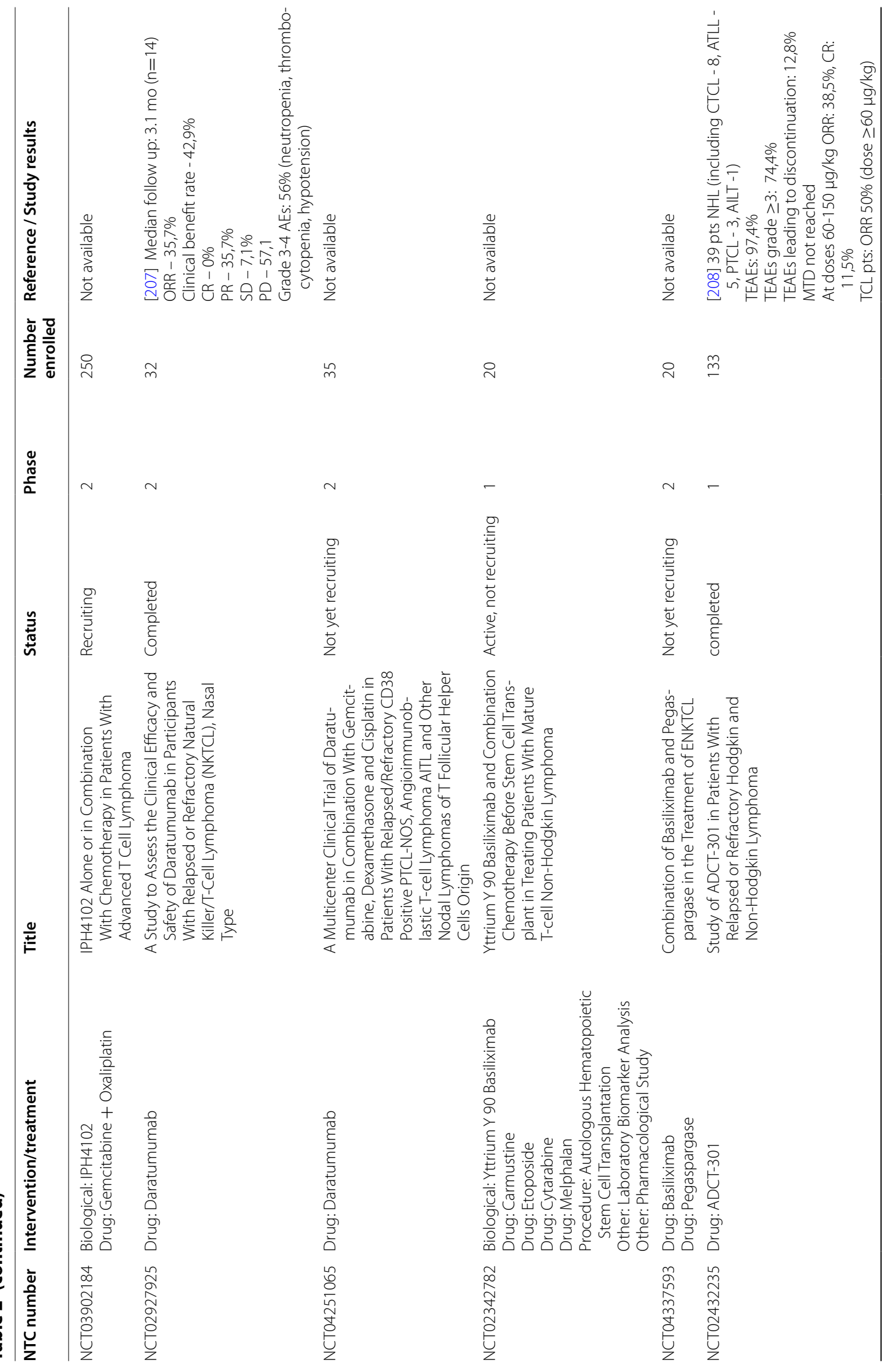




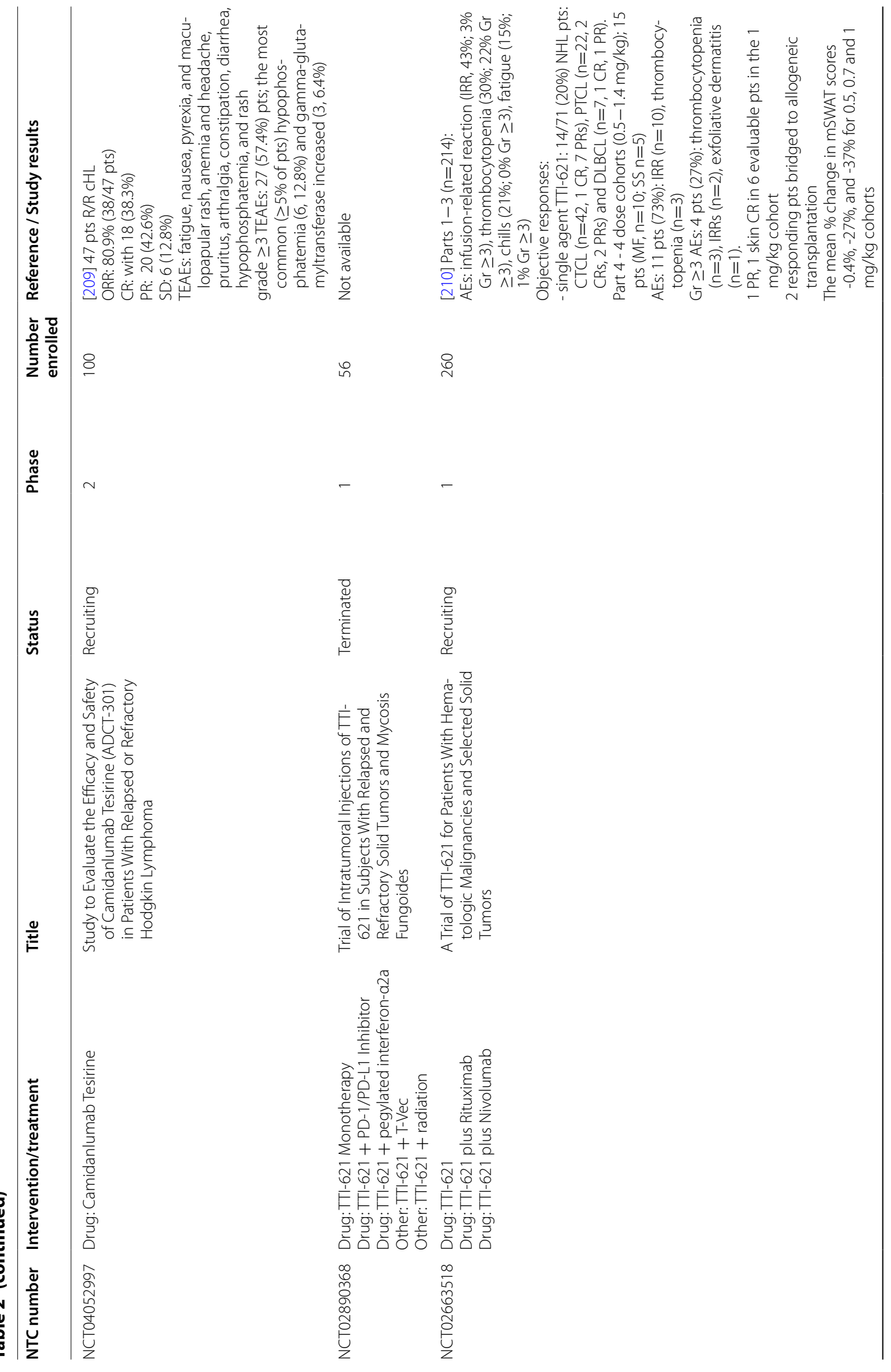




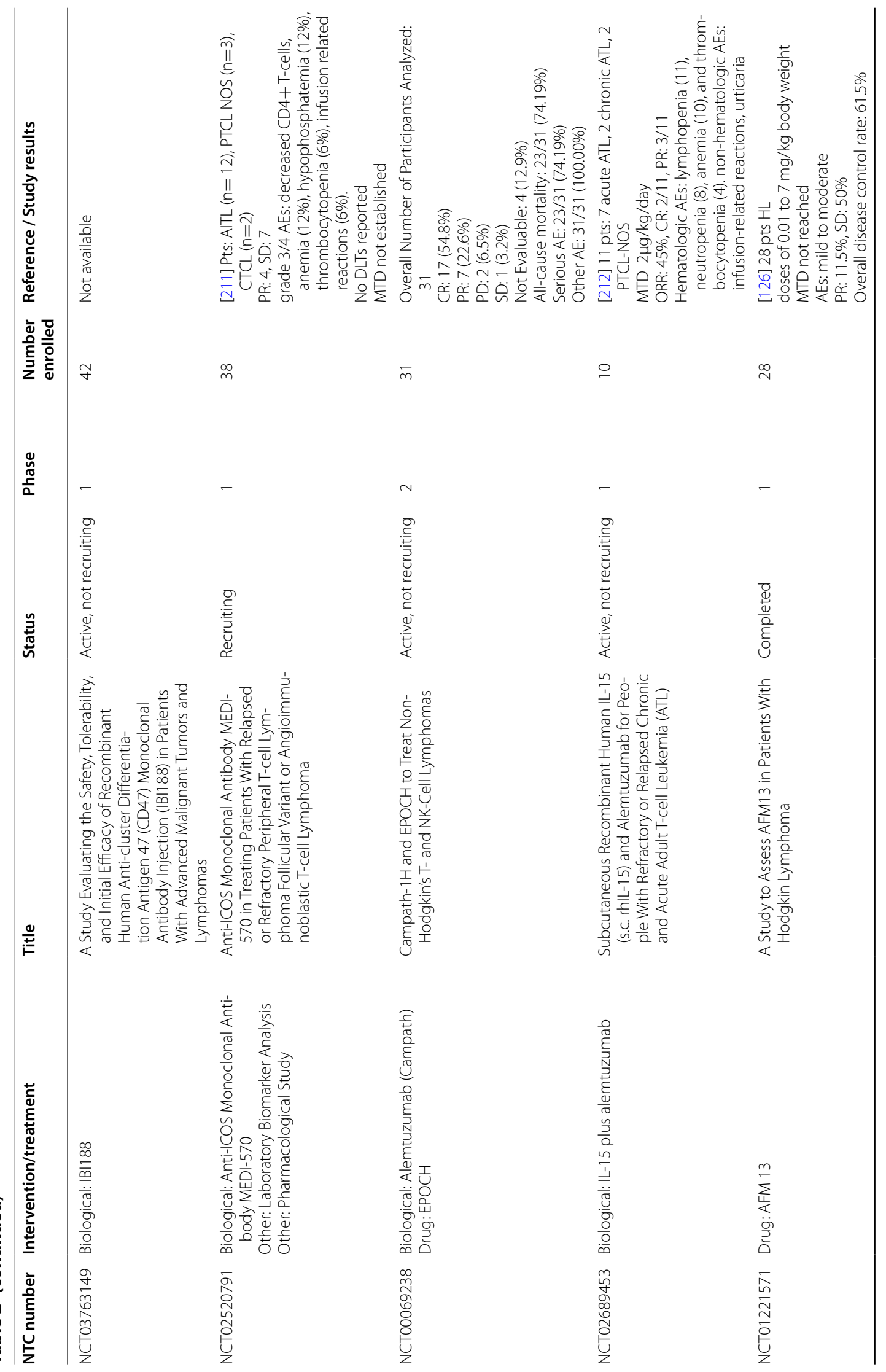




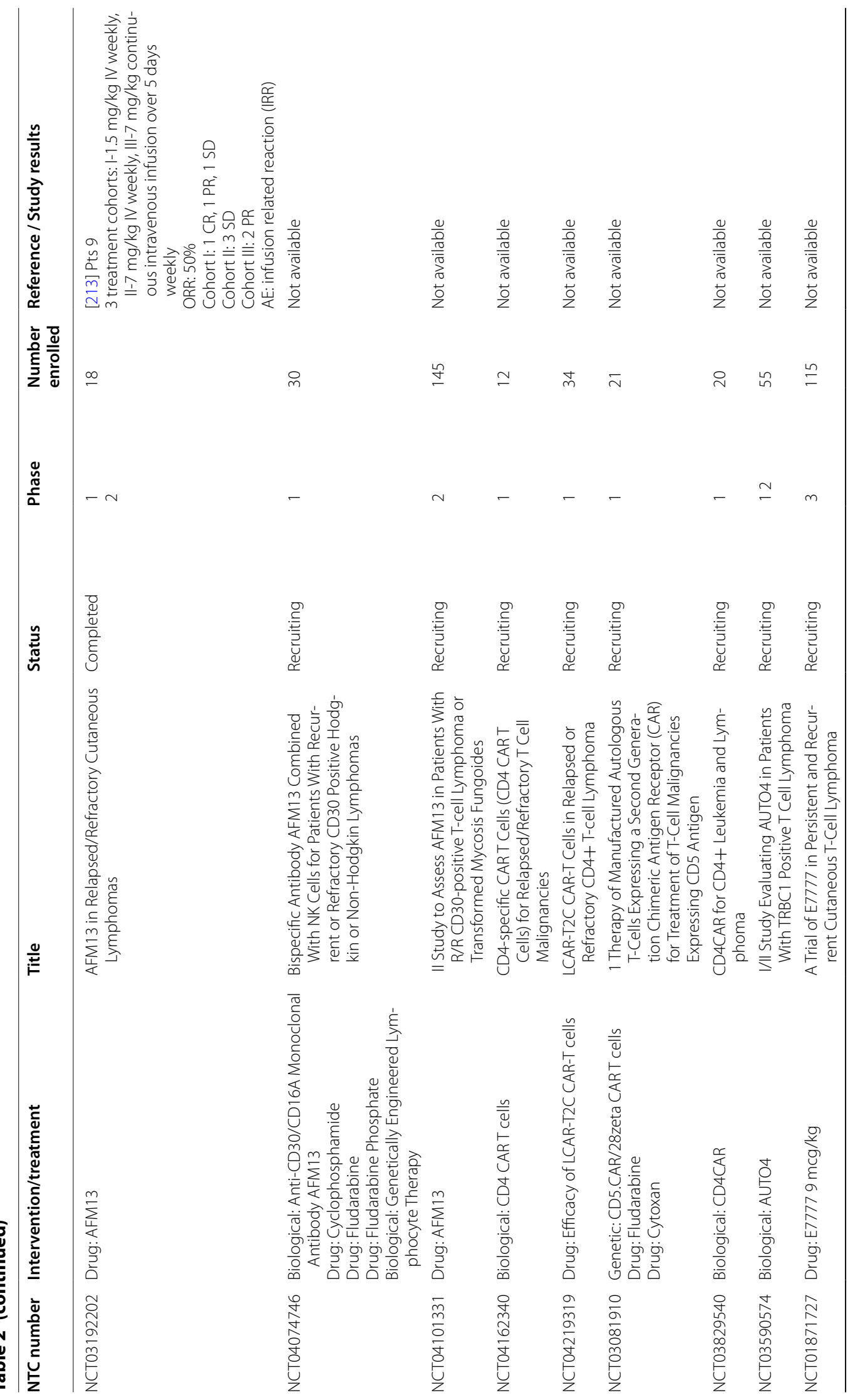




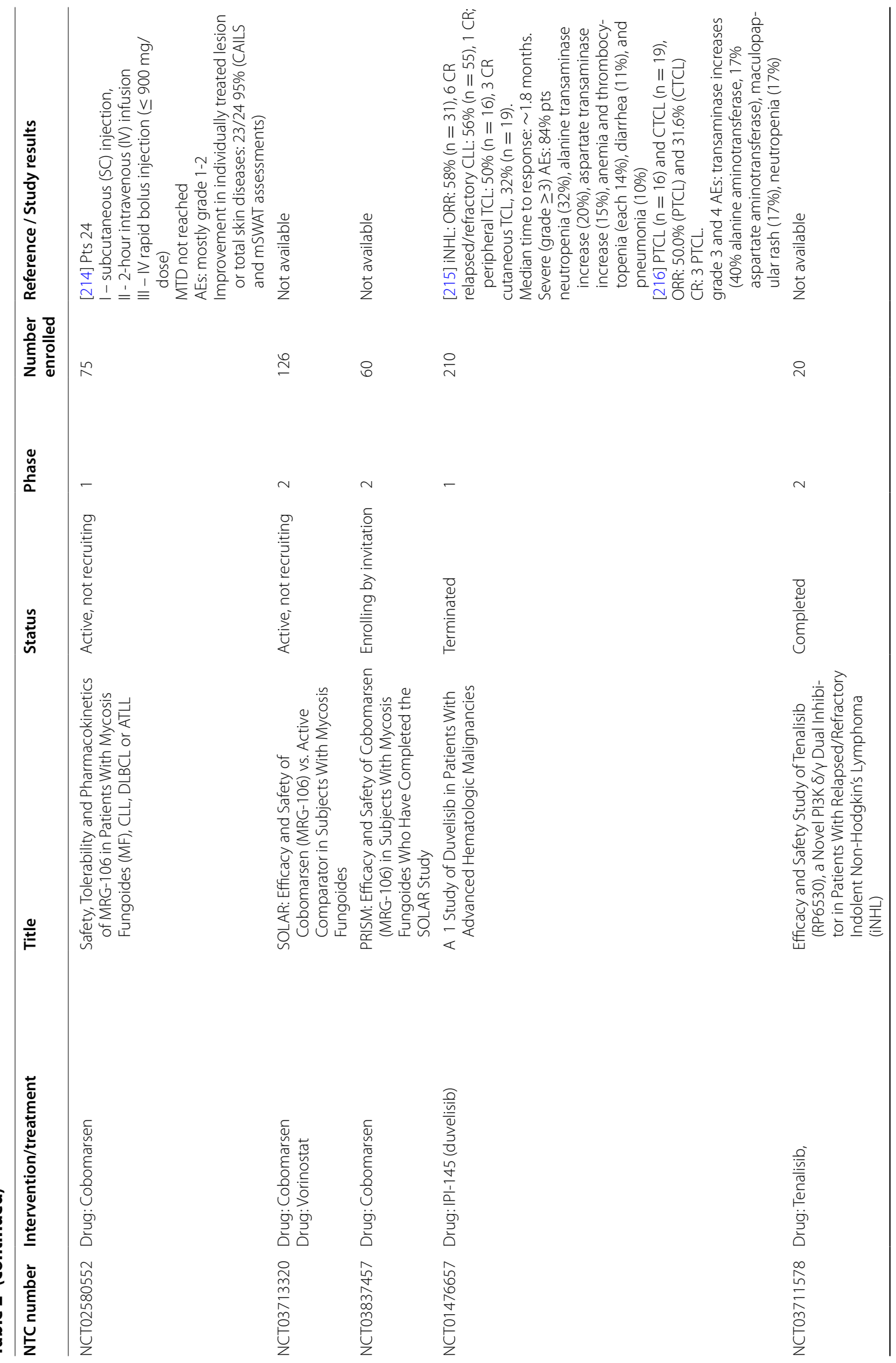




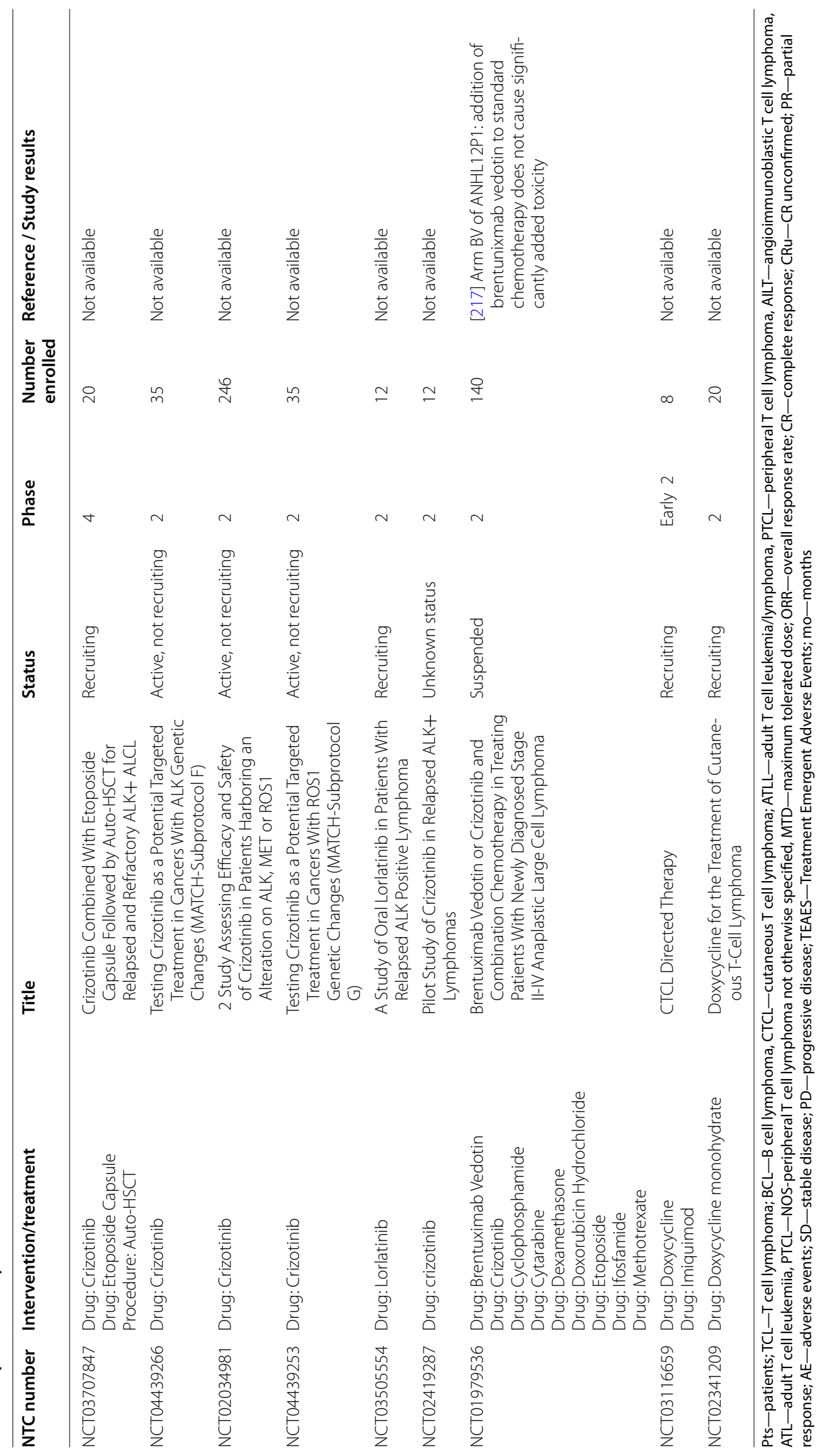


spectacular, it might be expected that in the near future, more effective TCL subtype-specific treatments will be elaborated.

\section{Acknowledgements \\ Not applicable.}

\section{Authors' contributions}

$\mathrm{Kl}, \mathrm{KR}$, and DK wrote parts of the original draft, prepared tables, and corrected the manuscript; DK and KR prepared figures; GKP performed conceptualization, wrote portions of the original draft, and prepared the final version of the manuscript. All authors read and approved the final manuscript.

\section{Funding}

This project was funded by the National Centre for Research and Development, Poland; Grant No. WPC/BCL/2019 (Kl, DK, and GKP) and the National Science Center, Poland; Decision no. DEC-2013/09/B/NZ1/01867 (GKP) and 2019/35/D/NZ5/00407 (KI).

\section{Availability of data and material}

Not applicable.

\section{Ethics approval and consent to participate}

Not applicable.

\section{Consent for publication}

All authors read and approved the final version of the manuscript.

\section{Competing interests}

The authors declare that they have no conflicts of interest.

Received: 6 October 2020 Accepted: 22 November 2020

Published online: 31 December 2020

\section{References}

1. Swerdlow SH, Campo E, Pileri SA, Harris NL, Stein H, Siebert R, et al. The 2016 revision of the World Health Organization classification of lymphoid neoplasms. Blood. 2016;127(20):2375-90.

2. Eckschlager T, PIch J, Stiborova M, Hrabeta J. Histone Deacetylase Inhibitors as Anticancer Drugs. Int J Mol Sci. 2017;18(7).

3. Oka T, Miyagaki T. Novel and future therapeutic drugs for advanced mycosis fungoides and sezary syndrome. Front Med (Lausanne). 2019;6:116

4. Photiou L, van der Weyden C, McCormack C, Miles PH. Systemic treatment options for advanced-stage mycosis fungoides and sezary syndrome. Curr Oncol Rep. 2018:20(4):32.

5. Li Y, Seto E. HDACs and HDAC inhibitors in cancer development and therapy. Cold Spring Harb Perspect Med. 2016;6(10).

6. Qu K, Zaba LC, Satpathy AT, Giresi PG, Li R, Jin Y, et al. Chromatin accessibility landscape of cutaneous $T$ cell lymphoma and dynamic response to HDAC inhibitors. Cancer Cell. 2017;32(1):27-41.

7. Duvic M, Vu J. Vorinostat: a new oral histone deacetylase inhibitor approved for cutaneous T-cell lymphoma. Expert Opin Investig Drugs. 2007;16(7):1111-20.

8. Olsen EA, Kim YH, Kuzel TM, Pacheco TR, Foss FM, Parker S, et al. Phase Ilb multicenter trial of vorinostat in patients with persistent, progressive, or treatment refractory cutaneous T-cell lymphoma. J Clin Oncol. 2007;25(21):3109-15.

9. Duvic M, Talpur R, Ni X, Zhang C, Hazarika P, Kelly C, et al. Phase 2 trial of oral vorinostat (suberoylanilide hydroxamic acid, SAHA) for refractory cutaneous T-cell lymphoma (CTCL). Blood. 2007;109(1):31-9.

10. Kim YH, Bagot M, Pinter-Brown L, Rook AH, Porcu P, Horwitz SM, et al. Mogamulizumab versus vorinostat in previously treated cutaneous T-cell lymphoma (MAVORIC): an international, open-label, randomised, controlled phase 3 trial. Lancet Oncol. 2018;19(9):1192-204.

11. Prince HM, Querfeld C. Integrating novel systemic therapies for the treatment of mycosis fungoides and Sezary syndrome. Best Pract Res Clin Haematol. 2018;31(3):322-35.
12. Foss F, Advani R, Duvic M, Hymes KB, Intragumtornchai T, Lekhakula A et al. A phase II trial of Belinostat (PXD101) in patients with relapsed or refractory peripheral or cutaneous T-cell lymphoma. Br J Haematol. 2015;168(6):811-9.

13. O'Connor OA, Horwitz S, Masszi T, Van Hoof A, Brown P, Doorduijn J, et al. Belinostat in patients with relapsed or refractory peripheral T-cell lymphoma: results of the pivotal phase II BELIEF (CLN-19) study. J Clin Oncol. 2015;33(23):2492-9.

14. Allen PB, Lechowicz MJ. Hematologic toxicity is rare in relapsed patients treated with belinostat: a systematic review of belinostat toxicity and safety in peripheral T-cell lymphomas. Cancer Manag Res. 2018;10:6731-42.

15. Piekarz RL, Frye R, Turner M, Wright JJ, Allen SL, Kirschbaum MH, et al. Phase II multi-institutional trial of the histone deacetylase inhibitor romidepsin as monotherapy for patients with cutaneous T-cell lymphoma. J Clin Oncol. 2009;27(32):5410-7.

16. Whittaker SJ, Demierre MF, Kim EJ, Rook AH, Lerner A, Duvic M, et al. Final results from a multicenter, international, pivotal study of romidepsin in refractory cutaneous T-cell lymphoma. J Clin Oncol. 2010;28(29):4485-91.

17. Piekarz RL, Frye R, Prince HM, Kirschbaum MH, Zain J, Allen SL, et al. Phase 2 trial of romidepsin in patients with peripheral T-cell lymphoma. Blood. 2011;117(22):5827-34.

18. Foss F, Duvic M, Lerner A, Waksman J, Whittaker S. Clinical efficacy of romidepsin in tumor stage and folliculotropic mycosis fungoides. Clin Lymphoma Myeloma Leuk. 2016;16(11):637-43.

19. Kim YH, Demierre MF, Kim EJ, Lerner A, Rook AH, Duvic M, et al. Clinically meaningful reduction in pruritus in patients with cutaneous T-cell lymphoma treated with romidepsin. Leuk Lymphoma. 2013;54(2):284-9.

20. Shimony S, Horowitz N, Ribakovsky E, Rozovski U, Avigdor A, Zloto K, et al. Romidepsin treatment for relapsed or refractory peripheral and cutaneous T-cell lymphoma: Real-life data from a national multicenter observational study. Hematol Oncol. 2019;37(5):569-77.

21. Duvic M, Dummer R, Becker JC, Poulalhon N, Ortiz Romero P, Grazia Bernengo $\mathrm{M}$, et al. Panobinostat activity in both bexarotene-exposed and -naive patients with refractory cutaneous T-cell lymphoma: results of a phase II trial. Eur J Cancer. 2013;49(2):386-94.

22. DeAngelo DJ, Spencer A, Bhalla KN, Prince HM, Fischer T, Kindler T, et al. Phase la/ll, two-arm, open-label, dose-escalation study of oral panobinostat administered via two dosing schedules in patients with advanced hematologic malignancies. Leukemia. 2013;27(8):1628-36.

23. Lu X, Ning Z, Li Z, Cao H, Wang X. Development of chidamide for peripheral T-cell lymphoma, the first orphan drug approved in China. Intractable Rare Dis Res. 2016;5(3):185-91.

24. Shi Y, Jia B, Xu W, Li W, Liu T, Liu P, et al. Chidamide in relapsed or refractory peripheral T cell lymphoma: a multicenter real-world study in China. J Hematol Oncol. 2017;10(1):69.

25. Shi Y, Dong $M$, Hong $X$, Zhang W, Feng J, Zhu J, et al. Results from a multicenter, open-label, pivotal phase II study of chidamide in relapsed or refractory peripheral T-cell lymphoma. Ann Oncol. 2015;26(8):1766-71.

26. Zhao J, Gray SG, Wabitsch M, Greene CM, Lawless MW. The therapeutic properties of resminostat for hepatocellular carcinoma. Oncoscience. 2018:5(5-6):196-208.

27. Arts J, King P, Marien A, Floren W, Belien A, Janssen L, et al. JNJ26481585, a novel "second-generation" oral histone deacetylase inhibitor, shows broad-spectrum preclinical antitumoral activity. Clin Cancer Res. 2009;15(22):6841-51.

28. Morales Torres C, Wu MY, Hobor S, Wainwright EN, Martin MJ, Patel $\mathrm{H}$, et al. Selective inhibition of cancer cell self-renewal through a Quisinostat-histone H10 axis. Nat Commun. 2020;11(1):1792.

29. Sborov DW, Canella A, Hade EM, Mo X, Khountham S, Wang J, et al. A phase 1 trial of the HDAC inhibitor AR-42 in patients with multiple myeloma and T- and B-cell lymphomas. Leuk Lymphoma. 2017:58(10):2310-8

30. Akilov OE, Grant C, Frye R, Bates S, Piekarz R, Geskin LJ. Low-dose electron beam radiation and romidepsin therapy for symptomatic cutaneous T-cell lymphoma lesions. Br J Dermatol. 2012;167(1):194-7.

31. Jothishankar B, Almazan T, Kim Y, Liauw S, Smith S, Kline J, et al. Romidepsin and total skin electron beam therapy in advanced stage mycosis fungoides and Sezary syndrome. Br J Haematol. 2019;186(2):377-9. 
32. Nachmias B, Shaulov A, Lavie D, Goldschmidt N, Gural A, Saban R, et al. Romidepsin-bendamustine combination for relapsed/refractory $T$ cell lymphoma. Acta Haematol. 2019;141(4):216-21.

33. Strati $P$, Chihara D, Oki Y, Fayad LE, Fowler N, Nastoupil L, et al. A phase I study of romidepsin and ifosfamide, carboplatin, etoposide for the treatment of patients with relapsed or refractory peripheral T-cell lymphoma. Haematologica. 2018;103(9):e416-8.

34. Amengual JE, Lichtenstein R, Lue J, Sawas A, Deng C, Lichtenstein $E$, et al. A phase 1 study of romidepsin and pralatrexate reveals marked activity in relapsed and refractory T-cell lymphoma. Blood. 2018;131(4):397-407.

35. O'Connor OA, Falchi L, Lue JK, Marchi E, Kinahan C, Sawas A, et al. Oral 5-azacytidine and romidepsin exhibit marked activity in patients with PTCL: a multicenter phase 1 study. Blood. 2019a;134(17):1395-405.

36. Nieto Y, Valdez BC, Thall PF, Jones RB, Wei W, Myers A, et al. Double epigenetic modulation of high-dose chemotherapy with azacitidine and vorinostat for patients with refractory or poor-risk relapsed lymphoma. Cancer. 2016;122(17):2680-8.

37. Strati P, Nastoupil LJ, Davis RE, Fayad LE, Fowler N, Hagemeister FB, et al. A phase 1 trial of alisertib and romidepsin for relapsed/ refractory aggressive B-cell and T-cell lymphomas. Haematologica. 2020;105(1):e26-8.

38. Ma H, Davarifar A, Amengual JE. The Future of Combination Therapies for Peripheral T Cell Lymphoma (PTCL). Curr Hematol Malig Rep. 2018;13(1):13-24.

39. Mehta-Shah NLMA, Boruchov MA, Ruan J, Nair S, Lynch P, Byrne R, Moskowitz AJ, Matasar MJ, Gerecitano JF, Hamlin PA, Leonard J, Moskowitz CH, Myskowski PL, Querfeld C, Nolan P, Palomba ML, Straus DJ, Zelenetz AD, Horwitz SM. A phase I/II trial of the combination of romidepsin and lenalidomide in patients with relapsed/refractory lymphoma and myeloma: Activity in T-cell lymphoma. J Clin Oncol. 2015;33(15):8521.

40. Rogers AM, Brammer JE. Hematopoietic cell transplantation and adoptive cell therapy in peripheral T cell lymphoma. Curr Hematol Malig Rep. 2020;15(4):316-32.

41. Khan NSAR, Khimani F, Shadman M, Cassaday RD, Ruan J, Moskowitz AJ, Zelenetz AD, Noy A, Straus DJ, Drullinsky P, Hamilton A, Kumar A, Sauter CS, Shah GL, Matasar MJ, Drill E, Davey T, Hancock H, Bahgat A, Blouin B, Schiavo KA, Smith H, VanBesien K, Giralt SA, Horwitz SM, Dahi PB. A Phase II, multicenter study of high dose chemotherapy with autologous stem cell transplant followed by maintenance therapy with romidepsin for T-cell lymphoma. Blood. 2019;134:4033.

42. Vu K, Wu CH, Yang CY, Zhan A, Cavallone E, Berry W, et al. Romidepsin plus liposomal doxorubicin is safe and effective in patients with relapsed or refractory T-cell lymphoma: results of a phase I dose-escalation study. Clin Cancer Res. 2020;26(5):1000-8.

43. Zhang H, Dong L, Chen Q, Kong L, Meng B, Wang H, et al. Synergistic antitumor effect of histone deacetylase inhibitor and Doxorubicin in peripheral T-cell lymphoma. Leuk Res. 2017;56:29-35.

44. Guan W, Jing Y, Dou L, Wang M, Xiao Y, Yu L. Chidamide in combination with chemotherapy in refractory and relapsed $T$ lymphoblastic Iymphoma/leukemia. Leuk Lymphoma. 2020;61(4):855-61.

45. Meka AK, Jenkins LJ, Davalos-Salas M, Pujara N, Wong KY, Kumeria T, et al. Enhanced Solubility, Permeability and Anticancer Activity of Vorinostat Using Tailored Mesoporous Silica Nanoparticles. Pharmaceutics. 2018;10(4).

46. Bhagat SD, Singh U, Mishra RK, Srivastava A. An endogenous reactive oxygen species (ROS)-activated histone deacetylase inhibitor prodrug for cancer chemotherapy. ChemMedChem. 2018;13(19):2073-9.

47. Xu J, Sun J, Wang P, Ma X, Li S. Pendant HDAC inhibitor SAHA derivatised polymer as a novel prodrug micellar carrier for anticancer drugs. J Drug Target. 2018;26(5-6):448-57.

48. Andrews JM, Schmidt JA, Carson KR, Musiek AC, Mehta-Shah N, Payton JE. Novel cell adhesion/migration pathways are predictive markers of HDAC inhibitor resistance in cutaneous T cell lymphoma. EBioMedicine. 2019:46:170-83.

49. Buus TB, Willerslev-Olsen A, Fredholm S, Blumel E, Nastasi C, Gluud $M$, et al. Single-cell heterogeneity in Sezary syndrome. Blood Adv. 2018;2(16):2115-26.

50. Zhao L, Okhovat JP, Hong EK, Kim YH, Wood GS. Preclinical studies support combined inhibition of BET family proteins and histone deacetylases as epigenetic therapy for cutaneous T-cell lymphoma. Neoplasia. 2019;21(1):82-92.

51. Kim SR, Lewis JM, Cyrenne BM, Monico PF, Mirza FN, Carlson KR, et al. BET inhibition in advanced cutaneous T cell lymphoma is synergistically potentiated by BCL2 inhibition or HDAC inhibition. Oncotarget. 2018;9(49):29193-207.

52. Cyrenne BM, Lewis JM, Weed JG, Carlson KR, Mirza FN, Foss FM, et al. Synergy of BCL2 and histone deacetylase inhibition against leukemic cells from cutaneous T-cell lymphoma patients. Blood. 2017;130(19):2073-83.

53. Ragheb R, Venton G, Chelbi R, Bonnet N, Le Treut T, Ivanov V, et al. Vorinostat and Mithramycin A in combination therapy as an interesting strategy for the treatment of Sezary T lymphoma: a transcriptomic approach. Arch Dermatol Res. 2017;309(8):611-23.

54. Pierce JM, Mehta A. Diagnostic, prognostic and therapeutic role of CD30 in lymphoma. Expert Rev Hematol. 2017;10(1):29-37.

55. Gilfillan MC, Noel PJ, Podack ER, Reiner SL, Thompson CB. Expression of the costimulatory receptor CD30 is regulated by both CD28 and cytokines. J Immunol. 1998;160(5):2180-7.

56. Horie R, Watanabe T. CD30: expression and function in health and disease. Semin Immunol. 1998;10(6):457-70.

57. Kumar A, Younes A. Role of CD30 targeting in malignant lymphoma. Curr Treat Options Oncol. 2014;15(2):210-25.

58. Gruss HJ, Boiani N, Williams DE, Armitage RJ, Smith CA, Goodwin RG Pleiotropic effects of the CD30 ligand on CD30-expressing cells and lymphoma cell lines. Blood. 1994;83(8):2045-56.

59. Bhatt G, Maddocks K, Christian B. CD30 and CD30-targeted therapies in hodgkin lymphoma and other B cell lymphomas. Curr Hematol Malig Rep. 2016;11(6):480-91.

60. Ferreira CR, Zhao S, Sanches JA, Miyashiro D, Cury-Martins J, Azevedo $\mathrm{RS}$, et al. Clinicopathologic and microenvironmental analysis of primary cutaneous CD30-positive lymphoproliferative disorders: a 26 year experience from an academic medical center in Brazil. Diagn Pathol. 2019;14(1):115.

61. Kim YH, Tavallaee M, Sundram U, Salva KA, Wood GS, Li S, et al. Phase Il investigator-initiated study of brentuximab vedotin in mycosis fungoides and sezary syndrome with variable CD30 expression level: a multi-institution collaborative project. J Clin Oncol. 2015;33(32):3750-8.

62. Lee WJ, Moon IJ, Shin HJ, Won CH, Chang SE, Choi JH, et al. CD30positive cutaneous extranodal natural killer/T-cell lymphoma: clinicopathological features and survival outcomes. Int J Dermatol. 2019;58(6):688-96.

63. Nishioka C, Takemoto S, Kataoka S, Yamanaka S, Moriki T, Shoda M, et al. Serum level of soluble CD30 correlates with the aggressiveness of adult T-cell leukemia/lymphoma. Cancer Sci. 2005;96(11):810-5.

64. Sabattini E, Pizzi M, Tabanelli V, Baldin P, Sacchetti CS, Agostinelli C, et al. CD30 expression in peripheral T-cell lymphomas. Haematologica. 2013;98(8):e81-2.

65. Tsuyama N, Sakamoto K, Sakata S, Dobashi A, Takeuchi K. Anaplastic large cell lymphoma: pathology, genetics, and clinical aspects. J Clin Exp Hematop. 2017;57(3):120-42.

66. Francisco JA, Cerveny CG, Meyer DL, Mixan BJ, Klussman K, Chace DF, et al. cAC10-vCMMAE, an anti-CD30-monomethyl auristatin E conjugate with potent and selective antitumor activity. Blood. 2003;102(4):1458-65.

67. Sutherland MS, Sanderson RJ, Gordon KA, Andreyka J, Cerveny CG, Yu C, et al. Lysosomal trafficking and cysteine protease metabolism confer target-specific cytotoxicity by peptide-linked anti-CD30-auristatin conjugates. J Biol Chem. 2006;281(15):10540-7.

68. Ajina R, AIDeghaither D, Jablonski S, Weiner LM. 6.02 Cancer Immunotherapy Comprehensive Medicinal Chemistry III Elsevier 2017.

69. Horwitz S, O'Connor OA, Pro B, Illidge T, Fanale M, Advani R, et al. Brentuximab vedotin with chemotherapy for CD30-positive peripheral T-cell Iymphoma (ECHELON-2): a global, double-blind, randomised, phase 3 trial. Lancet. 2019;393(10168):229-40.

70. Yoshie O, Matsushima K. CCR4 and its ligands: from bench to bedside. Int Immunol. 2015;27(1):11-20.

71. Remer M, Al-Shamkhani A, Glennie M, Johnson P. Mogamulizumab and the treatment of CCR4-positive T-cell lymphomas. Immunotherapy. 2014;6(11):1187-206. 
72. Makita S, Tobinai K. Mogamulizumab for the treatment of T-cell lymphoma. Expert Opin Biol Ther. 2017;17(9):1145-53.

73. Wilcox RA. Mogamulizumab: 2 birds, 1 stone. Blood 2015;125(12):1847-8.

74. Chan AT, Kollnberger SD, Wedderburn LR, Bowness P. Expansion and enhanced survival of natural killer cells expressing the killer immunoglobulin-like receptor KIR3DL2 in spondylarthritis. Arthritis Rheum. 2005;52(11):3586-95.

75. Battistella M, Janin A, Jean-Louis F, Collomb C, Leboeuf C, Sicard H, et al. KIR3DL2 (CD158k) is a potential therapeutic target in primary cutaneous anaplastic large-cell lymphoma. Br J Dermatol. 2016;175(2):325-33.

76. Bouaziz JD, Remtoula N, Bensussan A, Marie-Cardine A, Bagot M. Absolute CD3+ CD158k+ lymphocyte count is reliable and more sensitive than cytomorphology to evaluate blood tumour burden in Sezary syndrome. Br J Dermatol. 2010;162(1):123-8.

77. Moins-Teisserenc H, Daubord M, Clave E, Douay C, Felix J, Marie-Cardine A, et al. CD158k is a reliable marker for diagnosis of Sezary syndrome and reveals an unprecedented heterogeneity of circulating malignant cells. J Invest Dermatol. 2015;135(1):247-57.

78. Ortonne N, Le Gouvello S, Tabak R, Marie-Cardine A, Setiao J, Berrehar F, et al. CD158k/KIR3DL2 and NKp46 are frequently expressed in transformed mycosis fungoides. Exp Dermatol. 2012;21(6):461-3.

79. Thonnart N, Caudron A, Legaz I, Bagot M, Bensussan A, Marie-Cardine A. KIR3DL2 is a coinhibitory receptor on Sezary syndrome malignant T cells that promotes resistance to activation-induced cell death. Blood. 2014;124(22):3330-2.

80. Poszepczynska-Guigne E, Schiavon V, D'Incan M, Echchakir H, Musette $\mathrm{P}$, Ortonne N, et al. CD158k/KIR3DL2 is a new phenotypic marker of Sezary cells: relevance for the diagnosis and follow-up of Sezary syndrome. J Invest Dermatol. 2004;122(3):820-3.

81. Marie-Cardine A, Viaud N, Thonnart N, Joly R, Chanteux S, Gauthier L, et al. IPH4102, a humanized KIR3DL2 antibody with potent activity against cutaneous T-cell lymphoma. Cancer Res. 2014;74(21):6060-70.

82. Bagot M, Porcu P, Marie-Cardine A, Battistella M, William BM, Vermeer $\mathrm{M}$, et al. IPH4102, a first-in-class anti-KIR3DL2 monoclonal antibody, in patients with relapsed or refractory cutaneous T-cell lymphoma: an international, first-in-human, open-label, phase 1 trial. Lancet Oncol. 2019:20(8):1160-70

83. Calabretta E, Carlo-Stella C. The many facets of CD38 in lymphoma: from tumor-microenvironment cell interactions to acquired resistance to immunotherapy. Cells. 2020;9(4).

84. Cesano A, Visonneau S, Deaglio S, Malavasi F, Santoli D. Role of CD38 and its ligand in the regulation of MHC-nonrestricted cytotoxic T cells. J Immunol. 1998;160(3):1106-15.

85. Zaja F, Tabanelli V, Agostinelli C, Calleri A, Chiappella A, Varettoni M, et al. CD38, BCL-2, PD-1, and PD-1L expression in nodal peripheral T-cell lymphoma: possible biomarkers for novel targeted therapies? Am J Hematol. 2017;92(1):E1-2.

86. Mustafa N, Nee HFA, et al. Daratumumab efficiently targets NK/T Cell lymphoma with high CD38 expression. Blood. 2017;130:2814.

87. Frerichs KA, Verkleij CPM, Bosman PWC, Zweegman S, Otten H, van de Donk N. CD38-targeted therapy with daratumumab reduces autoantibody levels in multiple myeloma patients. J Transl Autoimmun. 2019;2:100022.

88. Krejcik J, Casneuf T, Nijhof IS, Verbist B, Bald J, Plesner T, et al. Daratumumab depletes $\mathrm{CD} 38+$ immune regulatory cells, promotes T-cell expansion, and skews T-cell repertoire in multiple myeloma. Blood. 2016;128(3):384-94.

89. de Weers M, Tai YT, van der Veer MS, Bakker JM, Vink T, Jacobs DC, et al. Daratumumab, a novel therapeutic human CD38 monoclonal antibody, induces killing of multiple myeloma and other hematological tumors. J Immunol. 2011;186(3):1840-8.

90. Overdijk MB, Verploegen S, Bogels M, van Egmond M, Lammerts van Bueren JJ, Mutis T, et al. Antibody-mediated phagocytosis contributes to the anti-tumor activity of the therapeutic antibody daratumumab in lymphoma and multiple myeloma. MAbs. 2015;7(2):311-21.

91. H. Huang WSK, M. Yao, et al. Daratumumab monotherapy for patients with relapsed or refractory (R/R) natural killer/T-cell lymphoma (NKTCL), nasal type: updated results from an open-label, single-arm, multicenter phase 2 study. Blood. 2019;134 1568.
92. Flynn MJ, Hartley JA. The emerging role of anti-CD25 directed therapies as both immune modulators and targeted agents in cancer. Br J Haematol. 2017:179(1):20-35.

93. Kim HP, Imbert J, Leonard WJ. Both integrated and differential regulation of components of the IL-2//L-2 receptor system. Cytokine Growth Factor Rev. 2006;17(5):349-66.

94. Gualco G, Chioato L, Weiss LM, Harrington WJ Jr, Bacchi CE. Analysis of human T-cell lymphotropic virus in CD25+ anaplastic large cell lymphoma in children. Am J Clin Pathol. 2009;132(1):28-33.

95. Wang L, Bi XW, Zhu YJ, He YZ, Lai QY, Xia ZJ, et al. IL-2Ralpha upregulation is mediated by latent membrane protein 1 and promotes lymphomagenesis and chemotherapy resistance in natural killer/T-cell lymphoma. Cancer Commun (Lond). 2018;38(1):62.

96. Wang Z, Shi BY, Qian YY, Cai M, Wang Q. Short-term anti-CD25 monoclonal antibody administration down-regulated CD25 expression without eliminating the neogenetic functional regulatory $T$ cells in kidney transplantation. Clin Exp Immunol. 2009;155(3):496-503.

97. Dancey G, Violet J, Malaroda A, Green AJ, Sharma SK, Francis R, et al. A Phase I Clinical Trial of CHT-25 a 131I-Labeled Chimeric Anti-CD25 Antibody Showing Efficacy in Patients with Refractory Lymphoma. Clin Cancer Res. 2009;15(24):7701-10.

98. Goldberg AD, Atallah E, Rizzieri D, Walter RB, Chung KY, Spira A, et al. Camidanlumab tesirine, an antibody-drug conjugate, in relapsed/ refractory CD25-positive acute myeloid leukemia or acute lymphoblastic leukemia: a phase I study. Leuk Res. 2020;95:106385.

99. Sick E, Jeanne A, Schneider C, Dedieu S, Takeda K, Martiny L. CD47 update: a multifaceted actor in the tumour microenvironment of potential therapeutic interest. Br J Pharmacol. 2012;167(7):1415-30.

100. Lian S, Xie X, Lu Y, Jia L. Checkpoint CD47 Function On Tumor Metastasis And Immune Therapy. Onco Targets Ther. 2019;12:9105-14.

101. Kamijo H, Miyagaki T, Takahashi-Shishido N, Nakajima R, Oka T, Suga H, et al. Thrombospondin-1 promotes tumor progression in cutaneous T-cell lymphoma via CD47. Leukemia. 2020;34(3):845-56.

102. Petrova PS, Viller NN, Wong M, Pang X, Lin GH, Dodge K, et al. TTI-621 (SIRPalphaFc): A CD47-blocking innate immune checkpoint inhibitor with broad antitumor activity and minimal erythrocyte binding. Clin Cancer Res. 2017;23(4):1068-79.

103. Folkes AS, Feng M, Zain JM, Abdulla F, Rosen ST, Querfeld C. Targeting CD47 as a cancer therapeutic strategy: the cutaneous T-cell lymphoma experience. Curr Opin Oncol. 2018;30(5):332-7.

104. Querfeld C, Thompson J, Taylor M, Pillai R, Johnson LD, Catalano T, et al. A Single Direct Intratumoral Injection of TTI-621 (SIRPaFc) Induces Antitumor Activity in Patients with Relapsed/Refractory Mycosis Fungoides and Sézary Syndrome: Preliminary Findings Employing an Immune Checkpoint Inhibitor Blocking the CD47 "Do Not Eat" Signal. Blood. 2017:130.

105. Coyle AJ, Lehar S, Lloyd C, Tian J, Delaney T, Manning S, et al. The CD28-related molecule ICOS is required for effective T cell-dependent immune responses. Immunity. 2000;13(1):95-105.

106. Yang JH, Zhang J, Cai Q, Zhao DB, Wang J, Guo PE, et al. Expression and function of inducible costimulator on peripheral blood T cells in patients with systemic lupus erythematosus. Rheumatology (Oxford). 2005:44(10):1245-54.

107. Kawamoto M, Harigai M, Hara M, Kawaguchi Y, Tezuka K, Tanaka M, et al. Expression and function of inducible co-stimulator in patients with systemic lupus erythematosus: possible involvement in excessive interferon-gamma and anti-double-stranded DNA antibody production. Arthritis Res Ther. 2006;8(3):R62

108. Solinas C, Gu-Trantien C, Willard-Gallo K. The rationale behind targeting the ICOS-ICOS ligand costimulatory pathway in cancer immunotherapy. ESMO Open. 2020;5(1).

109. Nicholson SM, Carlesso G, Cheng LI, Cook H, DaCosta K, Leininger J, et al. Effects of ICOS+ T cell depletion via afucosylated monoclonal antibody MEDI-570 on pregnant cynomolgus monkeys and the developing offspring. Reprod Toxicol. 2017;74:116-33.

110. Zhao Y, Su H, Shen X, Du J, Zhang X, Zhao Y. The immunological function of CD52 and its targeting in organ transplantation. Inflamm Res. 2017;66(7):571-8

111. Watanabe T, Masuyama J, Sohma Y, Inazawa H, Horie K, Kojima K, et al. CD52 is a novel costimulatory molecule for induction of CD4+ regulatory T cells. Clin Immunol. 2006;120(3):247-59. 
112. Cruz RI, Hernandez-Ilizaliturri FJ, Olejniczak S, Deeb G, Knight J, Wallace $P$, et al. CD52 over-expression affects rituximab-associated complement-mediated cytotoxicity but not antibody-dependent cellular cytotoxicity: preclinical evidence that targeting CD52 with alemtuzumab may reverse acquired resistance to rituximab in non-Hodgkin lymphoma. Leuk Lymphoma. 2007:48(12):2424-36.

113. Golay J, Manganini M, Rambaldi A, Introna M. Effect of alemtuzumab on neoplastic B cells. Haematologica. 2004;89(12):1476-83.

114. Mone AP, Cheney C, Banks AL, Tridandapani S, Mehter N, Guster S, et al. Alemtuzumab induces caspase-independent cell death in human chronic lymphocytic leukemia cells through a lipid raft-dependent mechanism. Leukemia. 2006;20(2):272-9.

115. Rowan W, Tite J, Topley P, Brett SJ. Cross-linking of the CAMPATH-1 antigen (CD52) mediates growth inhibition in human B- and T-lymphoma cell lines, and subsequent emergence of CD52-deficient cells. Immunology. 1998:95(3):427-36.

116. Smolewski P, Szmigielska-Kaplon A, Cebula B, Jamroziak K, Rogalinska $M$, Kilianska Z, et al. Proapoptotic activity of alemtuzumab alone and in combination with rituximab or purine nucleoside analogues in chronic lymphocytic leukemia cells. Leuk Lymphoma. 2005;46(1):87-100.

117. Zent CS, Secreto CR, LaPlant BR, Bone ND, Call TG, Shanafelt TD, et al. Direct and complement dependent cytotoxicity in CLL cells from patients with high-risk early-intermediate stage chronic lymphocytic leukemia (CLL) treated with alemtuzumab and rituximab. Leuk Res. 2008;32(12):1849-56.

118. Enblad G, Hagberg H, Erlanson M, Lundin J, MacDonald AP, Repp R, et al. A pilot study of alemtuzumab (anti-CD52 monoclonal antibody) therapy for patients with relapsed or chemotherapy-refractory peripheral T-cell lymphomas. Blood. 2004;103(8):2920-4.

119. Lenihan DJ, Alencar AJ, Yang D, Kurzrock R, Keating MJ, Duvic M. Cardiac toxicity of alemtuzumab in patients with mycosis fungoides/Sezary syndrome. Blood. 2004;104(3):655-8.

120. Lundin J, Hagberg H, Repp R, Cavallin-Stahl E, Freden S, Juliusson G, et al. Phase 2 study of alemtuzumab (anti-CD52 monoclonal antibody) in patients with advanced mycosis fungoides/Sezary syndrome. Blood. 2003;101(11):4267-72.

121. Wulf GG, Altmann B, Ziepert M, D'Amore F, Held G, Greil R, et al. Alemtuzumab plus $\mathrm{CHOP}$ versus $\mathrm{CHOP}$ in elderly patients with peripheral T-cell lymphoma: the DSHNHL2006-1B/ACT-2 trial. Leukemia. 2020.

122. Roswarski J, Roschewski M, Melani C, Pittaluga S, Lucas A, Steinberg SM, et al. Phase 1/2 study of alemtuzumab with dose-adjusted EPOCH in untreated aggressive T and NK cell lymphomas. Leuk Lymphoma. 2019;60(8):2062-6.

123. Phillips EH, Devereux S, Radford J, Mir N, Adedayo T, Clifton-Hadley $L$, et al. Toxicity and efficacy of alemtuzumab combined with CHOP for aggressive T-cell lymphoma: a phase 1 dose-escalation trial. Leuk Lymphoma. 2019;60(9):2291-4.

124. Romee R, Foley B, Lenvik T, Wang Y, Zhang B, Ankarlo D, et al. NK cell CD16 surface expression and function is regulated by a disintegrin and metalloprotease-17 (ADAM17). Blood. 2013;121(18):3599-608.

125. Wu J, Fu J, Zhang M, Liu D. AFM13: a first-in-class tetravalent bispecific anti-CD30/CD16A antibody for NK cell-mediated immunotherapy. J Hematol Oncol. 2015;8:96.

126. Rothe A, Sasse S, Topp MS, Eichenauer DA, Hummel H, Reiners KS, et al. A phase 1 study of the bispecific anti-CD30/CD16A antibody construct AFM13 in patients with relapsed or refractory Hodgkin lymphoma. Blood. 2015;125(26):4024-31.

127. Masuda M, Yageta M, Fukuhara H, Kuramochi M, Maruyama T, Nomoto $A$, et al. The tumor suppressor protein TSLC1 is involved in cell-cell adhesion. J Biol Chem. 2002;277(34):31014-9.

128. Nakahata S, Morishita K. CADM1/TSLC1 is a novel cell surface marker for adult T-cell leukemia/lymphoma. J Clin Exp Hematop. 2012;52(1):17-22.

129. Sasaki H, Nishikata I, Shiraga T, Akamatsu E, Fukami T, Hidaka T, et al. Overexpression of a cell adhesion molecule, TSLC1, as a possible molecular marker for acute-type adult T-cell leukemia. Blood. 2005;105(3):1204-13.

130. Dewan MZ, Takamatsu N, Hidaka T, Hatakeyama K, Nakahata S, Fujisawa J, et al. Critical role for TSLC1 expression in the growth and organ infiltration of adult T-cell leukemia cells in vivo. J Virol. 2008;82(23):11958-63.
131. Yuki A, Shinkuma S, Hayashi R, Fujikawa H, Kato T, Homma E, et al. CADM1 is a diagnostic marker in early-stage mycosis fungoides: Multicenter study of 58 cases. J Am Acad Dermatol. 2018;79(6):1039-46.

132. Nakahata S, Saito Y, Marutsuka K, Hidaka T, Maeda K, Hatakeyama K, et al. Clinical significance of CADM1/TSLC1/lgSF4 expression in adult T-cell leukemia/lymphoma. Leukemia. 2012;26(6):1238-46.

133. Chilmi S, Nakahata S, Fauzi YR, Ichikawa T, Tani C, Suwanruengsri M, et al. Development of anti-human CADM1 monoclonal antibodies as a potential therapy for adult T-cell leukemia/lymphoma. Int J Hematol. 2020.

134. Eshhar Z, Waks T, Gross G, Schindler DG. Specific activation and targeting of cytotoxic lymphocytes through chimeric single chains consisting of antibody-binding domains and the gamma or zeta subunits of the immunoglobulin and T-cell receptors. Proc Natl Acad Sci U S A. 1993;90(2):720-4.

135. You F, Wang $Y$, Jiang $L$, Zhu $X$, Chen D, Yuan $L$, et al. A novel CD7 chimeric antigen receptor-modified NK-92Ml cell line targeting T-cell acute lymphoblastic leukemia. Am J Cancer Res. 2019;9(1):64-78.

136. June CH, O'Connor RS, Kawalekar OU, Ghassemi S, Milone MC. CART cell immunotherapy for human cancer. Science. 2018;359(6382):1361-5.

137. Kasakovski D, Xu L, Li Y.T cell senescence and CAR-T cell exhaustion in hematological malignancies. J Hematol Oncol. 2018;11(1):91.

138. Sermer D, Brentjens R. CART-cell therapy: Full speed ahead. Hematol Oncol. 2019:37(Suppl 1):95-100.

139. Leisegang M, Wilde S, Spranger S, Milosevic S, Frankenberger B, Uckert W, et al. MHC-restricted fratricide of human lymphocytes expressing survivin-specific transgenic T cell receptors. J Clin Invest. 2010;120(11):3869-77.

140. Png YT, Vinanica N, Kamiya T, Shimasaki N, Coustan-Smith E, Campana D. Blockade of CD7 expression in T cells for effective chimeric antigen receptor targeting of T-cell malignancies. Blood Adv. 2017;1 (25):2348-60

141. Cooper ML, Choi J, Staser K, Ritchey JK, Devenport JM, Eckardt K, et al. An "off-the-shelf" fratricide-resistant CAR-T for the treatment of T cell hematologic malignancies. Leukemia. 2018;32(9):1970-83.

142. Ma G, Shen J, Pinz K, Wada M, Park J, Kim S, et al. Targeting T Cell Malignancies Using CD4CAR T-Cells and Implementing a Natural Safety Switch. Stem Cell Rev Rep. 2019;15(3):443-7.

143. Pinz KG, Yakaboski E, Jares A, Liu H, Firor AE, Chen KH, et al. Targeting T-cell malignancies using anti-CD4 CAR NK-92 cells. Oncotarget. 2017;8(68):112783-96.

144. Raikar SS, Fleischer LC, Moot R, Fedanov A, Paik NY, Knight KA, et al. Development of chimeric antigen receptors targeting T-cell malignancies using two structurally different anti-CD5 antigen binding domains in NK and CRISPR-edited T cell lines. Oncoimmunology. 2018;7(3):e1407898.

145. Hill LC RR, Smith TS, Yang L, Srinivasan M, Zhang H, et al. Safety and antitumor activity of CD5 CAR T-cells in patients with relapsed/refractory T-cell malignancies. Blood2019. p. 199.

146. Hombach A, Heuser C, Sircar R, Tillmann T, Diehl V, Pohl C, et al. Characterization of a chimeric T-cell receptor with specificity for the Hodgkin's lymphoma-associated CD30 antigen. J Immunother. 1999;22(6):473-80.

147. Savoldo B, Rooney CM, Di Stasi A, Abken H, Hombach A, Foster AE, et al. Epstein Barr virus specific cytotoxic T lymphocytes expressing the anti-CD30zeta artificial chimeric T-cell receptor for immunotherapy of Hodgkin disease. Blood. 2007;110(7):2620-30.

148. Grover NS, Savoldo B. Challenges of driving CD30-directed CAR-T cells to the clinic. BMC Cancer. 2019;19(1):203.

149. Beckmann J, Scheitza S, Wernet P, Fischer JC, Giebel B. Asymmetric cell division within the human hematopoietic stem and progenitor cell compartment: identification of asymmetrically segregating proteins. Blood. 2007;109(12):5494-501.

150. Hombach AA, Gorgens A, Chmielewski M, Murke F, Kimpel J, Giebel $B$, et al. Superior Therapeutic Index in Lymphoma Therapy: CD30(+) CD34(+) Hematopoietic Stem Cells Resist a Chimeric Antigen Receptor T-cell Attack. Mol Ther. 2016;24(8):1423-34.

151. Maciocia PM, Wawrzyniecka PA, Philip B, Ricciardelli I, Akarca AU, Onuoha SC, et al. Targeting the T cell receptor beta-chain constant region for immunotherapy of $\mathrm{T}$ cell malignancies. Nat Med. 2017;23(12):1416-23. 
152. Allahyari H, Heidari S, Ghamgosha M, Saffarian P, Amani J. Immunotoxin: A new tool for cancer therapy. Tumour Biol. 2017;39(2):1010428317692226.

153. Wang H, Wang Z, Zhang H, Qi Z, Johnson AC, Mathes D, et al. Bispecific human IL2-CCR4 immunotoxin targets human cutaneous T-cell lymphoma. Mol Oncol. 2020;14(5):991-1000.

154. Duvic M, Geskin L, Prince HM. Duration of response in cutaneous T-cell lymphoma patients treated with denileukin diftitox: results from 3 phase III studies. Clin Lymphoma Myeloma Leuk. 2013;13(4):377-84

155. Prince HM, Duvic M, Martin A, Sterry W, Assaf C, Sun Y, et al. Phase III placebo-controlled trial of denileukin diftitox for patients with cutaneous T-cell lymphoma. J Clin Oncol. 2010;28(11):1870-7.

156. Manoukian G, Hagemeister F. Denileukin diftitox: a novel immunotoxin. Expert Opin Biol Ther. 2009:9(11):1445-51.

157. Ohmachi K, Ando K, Ogura M, Uchida T, Tobinai K, Maruyama D, et al. E7777 in Japanese patients with relapsed/refractory peripheral and cutaneous T-cell lymphoma: A phase I study. Cancer Sci. 2018;109(3):794-802.

158. Felekkis K, Touvana E, Stefanou C, Deltas C. microRNAs: a newly described class of encoded molecules that play a role in health and disease. Hippokratia. 2010;14(4):236-40.

159. Alivernini S, Gremese E, McSharry C, Tolusso B, Ferraccioli G, Mclnnes IB, et al. MicroRNA-155-at the Critical Interface of Innate and Adaptive Immunity in Arthritis. Front Immunol. 2017:8:1932.

160. Dai R, Ahmed SA. MicroRNA, an Important Epigenetic Regulator of Immunity and Autoimmunity. Translating MicroRNAs to the Clinic. 2017:223-58.

161. Czochor JR, Sulkowski P, Glazer PM. miR-155 Overexpression Promotes Genomic Instability by Reducing High-fidelity Polymerase Delta Expression and Activating Error-Prone DSB Repair. Mol Cancer Res. 2016;14(4):363-73.

162. Chang Y, Cui M, Fu X, Zhang L, Li X, Li L, et al. MiRNA-155 regulates lymphangiogenesis in natural killer/T-cell lymphoma by targeting BRG1. Cancer Biol Ther. 2019;20(1):31-41.

163. Kohnken R, Mishra A. MicroRNAs in Cutaneous T-Cell Lymphoma: The Future of Therapy. J Invest Dermatol. 2019;139(3):528-34.

164. Seto AG, Beatty X, Lynch JM, Hermreck M, Tetzlaff M, Duvic M, et al. Cobomarsen, an oligonucleotide inhibitor of miR-155, co-ordinately regulates multiple survival pathways to reduce cellular proliferation and survival in cutaneous T-cell lymphoma. Br J Haematol. 2018;183(3):428-44.

165. Meier TI, Cook JA, Thomas JE, Radding JA, Horn C, Lingaraj T, et al. Cloning, expression, purification, and characterization of the human Class la phosphoinositide 3-kinase isoforms. Protein Expr Purif. 2004;35(2):218-24.

166. Stark AK, Sriskantharajah S, Hessel EM, Okkenhaug K. PI3K inhibitors in inflammation, autoimmunity and cancer. Curr Opin Pharmacol. 2015;23:82-91.

167. Kaneda MM, Messer KS, Ralainirina N, Li H, Leem CJ, Gorjestani S, et al. $\mathrm{PI3Kgamma}$ is a molecular switch that controls immune suppression. Nature. 2016;539(7629):437-42.

168. Winkler DG, Faia KL, DiNitto JP, Ali JA, White KF, Brophy EE, et al. PI3K-delta and PI3K-gamma inhibition by IPI-145 abrogates immune responses and suppresses activity in autoimmune and inflammatory disease models. Chem Biol. 2013;20(11):1364-74.

169. Horwitz SM, Koch R, Porcu P, Oki Y, Moskowitz A, Perez M, et al. Activity of the PI3K-delta, gamma inhibitor duvelisib in a phase 1 trial and preclinical models of T-cell lymphoma. Blood. 2018a;131(8):888-98.

170. Carlo-Stella C, Delarue R, Scarfo L, Barde PJ, Nair A, Locatelli SL, et al. A First-in-human Study of Tenalisib (RP6530), a Dual PI3K delta/gamma Inhibitor, in Patients With Relapsed/Refractory Hematologic Malignancies: Results From the European Study. Clin Lymphoma Myeloma Leuk. 2020;20(2):78-86.

171. Huen A, Haverkos BM, Zain J, Radhakrishnan R, Lechowicz MJ, Devata S, et al. Phase I/Ib Study of Tenalisib (RP6530), a Dual PI3K delta/gamma Inhibitor in Patients with Relapsed/Refractory T-Cell Lymphoma. Cancers (Basel). 2020;12(8).

172. Lemmon MA, Schlessinger J. Cell signaling by receptor tyrosine kinases. Cell. 2010;141(7):1117-34.

173. Bryan MC, Whittington DA, Doherty EM, Falsey JR, Cheng AC, Emkey $R$, et al. Rapid development of piperidine carboxamides as potent and selective anaplastic lymphoma kinase inhibitors. J Med Chem. 2012;55(4):1698-705.

174. Pan P, Yu H, Liu Q, Kong X, Chen H, Chen J, et al. Combating DrugResistant Mutants of Anaplastic Lymphoma Kinase with Potent and Selective Type-I(1/2) Inhibitors by Stabilizing Unique DFG-Shifted Loop Conformation. ACS Cent Sci. 2017;3(11):1208-20.

175. Tu CH, Lin WH, Peng YH, Hsu T, Wu JS, Chang CY, et al. Pyrazolylamine Derivatives Reveal the Conformational Switching between Type I and Type II Binding Modes of Anaplastic Lymphoma Kinase (ALK). J Med Chem. 2016;59(8):3906-19.

176. Kang CH, Lee DH, Lee CO, Du Ha J, Park CH, Hwang JY. Induced protein degradation of anaplastic lymphoma kinase (ALK) by proteolysis targeting chimera (PROTAC). Biochem Biophys Res Commun. 2018;505(2):542-7.

177. Powell CE, Gao Y, Tan L, Donovan KA, Nowak RP, Loehr A, et al. Chemically Induced Degradation of Anaplastic Lymphoma Kinase (ALK). J Med Chem. 2018;61(9):4249-55.

178. Zhang $C$, Han XR, Yang X, Jiang B, Liu J, Xiong Y, et al. Proteolysis Targeting Chimeras (PROTACs) of Anaplastic Lymphoma Kinase (ALK). Eur J Med Chem. 2018;151:304-14.

179. Gambacorti-Passerini C, Messa C, Pogliani EM. Crizotinib in anaplastic large-cell lymphoma. N Engl J Med. 2011;364(8):775-6.

180. Mosse YP, Lim MS, Voss SD, Wilner K, Ruffner K, Laliberte J, et al. Safety and activity of crizotinib for paediatric patients with refractory solid tumours or anaplastic large-cell lymphoma: a Children's Oncology Group phase 1 consortium study. Lancet Oncol. 2013;14(6):472-80.

181. Mosse YP, Voss SD, Lim MS, Rolland D, Minard CG, Fox E, et al. Targeting ALK With Crizotinib in Pediatric Anaplastic Large Cell Lymphoma and Inflammatory Myofibroblastic Tumor: A Children's Oncology Group Study. J Clin Oncol. 2017;35(28):3215-21.

182. Gambacorti-Passerini C, Mussolin L, Brugieres L. Abrupt Relapse of ALKPositive Lymphoma after Discontinuation of Crizotinib. N Engl J Med. 2016;374(1):95-6.

183. Richly H, Kim TM, Schuler M, Kim DW, Harrison SJ, Shaw AT, et al. Ceritinib in patients with advanced anaplastic lymphoma kinase-rearranged anaplastic large-cell lymphoma. Blood. 2015;126(10):1257-8.

184. Gambacorti-Passerini C, Orlov S, Zhang L, Braiteh F, Huang H, Esaki T, et al. Long-term effects of crizotinib in ALK-positive tumors (excluding NSCLC): A phase $1 \mathrm{~b}$ open-label study. Am J Hematol. 2018;93(5):607-14.

185. Gambacorti Passerini C, Farina F, Stasia A, Redaelli S, Ceccon M, Mologni L, et al. Crizotinib in advanced, chemoresistant anaplastic lymphoma kinase-positive lymphoma patients. J Natl Cancer Inst. 2014;106(2):djt378.

186. Ceccon M, Mologni L, Bisson W, Scapozza L, Gambacorti-Passerini C. Crizotinib-resistant NPM-ALK mutants confer differential sensitivity to unrelated Alk inhibitors. Mol Cancer Res. 2013;11(2):122-32.

187. Huang X, Shen Q, Chen S, Chen S, Yang L, Weng J, et al. Gene expression profiles in BCL11B-siRNA treated malignant T cells. J Hematol Oncol. 2011;4:23.

188. Przybylski GK, Dik WA, Wanzeck J, Grabarczyk P, Majunke S, MartinSubero Jl, et al. Disruption of the BCL11B gene through inv(14) (q11.2q32.31) results in the expression of BCL11B-TRDC fusion transcripts and is associated with the absence of wild-type BCL11B transcripts in T-ALL. Leukemia. 2005;19(2):201-8.

189. Grabarczyk P, Przybylski GK, Depke M, Volker U, Bahr J, Assmus K, et al. Inhibition of BCL11B expression leads to apoptosis of malignant but not normal mature T cells. Oncogene. 2007;26(26):3797-810.

190. Mirvish JJ, Pomerantz RG, Falo LD Jr, Geskin LJ. Role of infectious agents in cutaneous T-cell lymphoma: facts and controversies. Clin Dermatol. 2013;31(4):423-31.

191. Nguyen V, Huggins RH, Lertsburapa T, Bauer K, Rademaker A, Gerami P, et al. Cutaneous T-cell lymphoma and Staphylococcus aureus colonization. J Am Acad Dermatol. 2008;59(6):949-52.

192. Woetmann A, Lovato P, Eriksen KW, Krejsgaard T, Labuda T, Zhang Q, et al. Nonmalignant T cells stimulate growth of T-cell lymphoma cells in the presence of bacterial toxins. Blood. 2007;109(8):3325-32.

193. Talpur R, Bassett R, Duvic M. Prevalence and treatment of Staphylococcus aureus colonization in patients with mycosis fungoides and Sezary syndrome. Br J Dermatol. 2008;159(1):105-12. 
194. Lindahl LM, Willerslev-Olsen A, Gjerdrum LMR, Nielsen PR, Blumel E, Rittig $\mathrm{AH}$, et al. Antibiotics inhibit tumor and disease activity in cutaneous T-cell lymphoma. Blood. 2019;134(13):1072-83.

195. Iyer SP, Huen A, Haverkos B, Ai WZ, Okada C, Kuzel TM, et al. A MultiCenter, Open Label, Phase I/II Study to Assess the Safety and Efficacy of Tenalisib Given in Combination with Romidepsin in Patients with Relapsed/Refractory T-Cell Lymphoma. Blood. 2020;136(Supplement 1):8-10.

196. Bachy E, Camus V, Thieblemont C, Casasnovas R-O, Ysebaert L, Damaj GL, et al. Final Analysis of the Ro-CHOP Phase III Study (Conducted by LYSA): Romidepsin Plus CHOP in Patients with Peripheral T-Cell Lymphoma. Blood. 2020;136(Supplement 1):32-3.

197. Barta SK, Feldman TA, DeSimone JA, Kim E, Devajaran K, Wiest D, et al. A Phase I Trial Assessing the Feasibility of Romidepsin Combined with Brentuximab Vedotin for Patients Requiring Systemic Therapy for Cutaneous T-Cell Lymphoma. Blood. 2020;136(Supplement 1):24-5.

198. Mehta-Shah N, Moskowitz AJ, Lunning MA, Lynch P, Scheuerman M, Minnal V, et al. A Phase Ib/lla Trial of the Combination of Romidepsin, Lenalidomide and Carfilzomib in Patients with Relapsed/Refractory Lymphoma Shows Complete Responses in Relapsed and Refractory Band T-Cell Lymphomas. Blood. 2017;130(Supplement 1):821-.

199. Mehta-Shah N, Lunning MA, Boruchov AM, Ruan J, Nair S, Lynch P, et al. A phase I/II trial of the combination of romidepsin and lenalidomide in patients with relapsed/refractory lymphoma and myeloma: Activity in T-cell lymphoma. Journal of Clinical Oncology. 2015;33(15_suppl):8521-

200. Ghione P, Faruque P, Mehta-Shah N, Seshan V, Ozkaya N, Bhaskar S, et al. T follicular helper phenotype predicts response to histone deacetylase inhibitors in relapsed/refractory peripheral T-cell lymphoma. Blood Advances. 2020;4(19):4640-7.

201. Chiappella A, Carniti C, Evangelista A, Cabras MG, Re A, Zanni M, et al. Romidepsin-CHOEP Plus Intensification with up-Front Stem-Cell Transplantation in Peripheral T-Cell Lymphoma: Final Results of Phase Ib PTCL13 Study of the Fondazione Italiana Linfomi. Blood. 2018;132(Supplement 1):2902-

202. Iyer SP, Xu J, Becnel MR, Nair R, Steiner R, Feng L, et al. A Phase II Study of Pembrolizumab in Combination with Romidepsin Demonstrates Durable Responses in Relapsed or Refractory T-Cell Lymphoma (TCL). Blood. 2020;136(Supplement 1):40-1.

203. Zhang W, Su L, Liu L, Gao Y, Wang Q, Su H, et al. Combination of Chida mide with the CHOEP Regimen in Previously Untreated Patients with Peripheral T-Cell Lymphoma (PTCL): A Prospective, Multicenter, SingleArm, Phase 1b/2 Trial. Blood. 2019;134(Supplement_1):4036-.

204. Zhou H, Gao Y, Wang Q, Cao R, Zhen Z, Li Q, et al. A Novel Oral Histone Deacetylase Inhibitor Chidamide Is Highly Effective and Well-Tolerated in Adult Early T-Cell Precursor and Ph-like Acute Lymphoblastic Leukemia. Blood. 2018;132(Supplement 1):4011-

205. Child F, Romero PO, Alvarez R, Bagot M, Stadler R, Weichenthal $M$, et al. Phctat, a Histone Deacetylase Inhibitor, in Patients with Previously Treated Stage IB-IVA Cutaneous T-Cell Lymphoma. Blood. 2012;120(21):3676-

206. O'Connor OA, Falchi L, Lue JK, Marchi E, Kinahan C, Sawas A, et al. Oral 5-azacytidine and romidepsin exhibit marked activity in patients with PTCL: a multicenter phase 1 study. Blood. 2019b;134(17):1395-405.

207. Kim W-S, Eom H-S, Yeh S-P, Cho S-G, Heo DS, Kim JS, et al. Daratumumab Monotherapy for Patients with Relapsed or Refractory (R/R)
Natural Killer/T-Cell Lymphoma (NKTCL), Nasal Type: An Open-Label, Single-Arm, Multicenter Phase 2 Study. Blood. 2018;132(Supplement 1):1617-.

208. Collins GP, Horwitz SM, Davies A, Karnad A, Samaniego F, Spira Al, et al. Adct-301 (Camidanlumab Tesirine), a Novel PyrrolobenzodiazepineBased CD25-Targeting Antibody Drug Conjugate, in a Phase 1 Study of Relapsed/Refractory Non-Hodgkin Lymphoma Shows Activity in T-Cell Lymphoma. Blood. 2018;132(Supplement 1):1658-.

209. Herrera AF, Carlo-Stella C, Collins GP, Maddocks KJ, Bartlett NL, Savage $\mathrm{KJ}$, et al. Preliminary Results of a Phase 2 Study of Camidanlumab Tesirine (Cami), a Novel Pyrrolobenzodiazepine-Based Antibody-Drug Conjugate, in Patients with Relapsed or Refractory Hodgkin Lymphoma. Blood. 2020;136(Supplement 1):21-3.

210. Horwitz SM, Foran JM, Maris M, Sawas A, Okada C, Feldman TA, et al. Updates from Ongoing, First-in-Human Phase 1 Dose Escalation and Expansion Study of TTI-621, a Novel Biologic Targeting CD47, in Patients with Relapsed or Refractory Hematologic Malignancies. Blood. 2020;136(Supplement 1):41-3.

211. Chavez JC, Foss FM, William BM, Brammer JE, Smith SM, Prica A, et al. A Phase I Study of Anti-ICOS Antibody MEDI-570 for Relapsed/Refractory (R/R) Peripheral T-Cell Lymphoma (PTCL) and Angioimmunoblastic T-Cell Lymphoma (AITL) (NCl-9930). Blood. 2020;136(Supplement 1):5-6.

212. Miljkovic MD, Conlon KC, Albert J, Allen D, Waldmann TA. Phase 1 Study of Subcutaneous Recombinant Human (rh) Interleukin-15 and Intravenous Alemtuzumab in Patients with Rrelapsed/Refractory T-Cell Lymphoma. Blood. 2020;136(Supplement 1):23-4.

213. Sawas A, Elgedawe H, Vlad G, Lipschitz M, Chen P-H, Rodig SJ, et al. Clinical and Biological Evaluation of the Novel CD30/CD16A Tetravalent Bispecific Antibody (AFM13) in Relapsed or Refractory CD30-Positive Lymphoma with Cutaneous Presentation: A Biomarker Phase Ib/lla Study (NCT03192202). Blood. 2018;132(Supplement 1):2908

214. Querfeld C, et al. Phase 1 study of the safety and efficacy of MRG106, a synthetic inhibitor of micro RNA-155, in CTCL patients. Blood. 2017;130(Supplement 1):820.

215. Flinn IW, O'Brien S, Kahl B, Patel M, Oki Y, Foss FF, et al. Duvelisib, a novel oral dual inhibitor of PI3K- $\delta, \gamma$, is clinically active in advanced hematologic malignancies. Blood. 2018;131(8):877-87.

216. Horwitz SM, Koch R, Porcu P, Oki Y, Moskowitz A, Perez M, et al. Activity of the PI3K- $\delta, \gamma$ inhibitor duvelisib in a phase 1 trial and preclinical models of T-cell lymphoma. Blood. 2018b;131(8):888-98.

217. Lowe EJ, Reilly A, Bollard CM, Barkauskas DA, Buxton AB, Hall D, et al. Toxicity Profile of Brentuximab Vedotin in Combination with Chemotherapy for Newly Diagnosed Patients with ALK+ ALCL: A Children's Oncology Group Study ANHL12P1. Blood. 2018;132(Supplement 1):1625-.

\section{Publisher's Note}

Springer Nature remains neutral with regard to jurisdictional claims in published maps and institutional affiliations.

Ready to submit your research? Choose BMC and benefit from

- fast, convenient online submission

- thorough peer review by experienced researchers in your field

- rapid publication on acceptance

- support for research data, including large and complex data types

- gold Open Access which fosters wider collaboration and increased citations

- maximum visibility for your research: over $100 \mathrm{M}$ website views per year

At BMC, research is always in progress.

Learn more biomedcentral.com/submissions 